\title{
Mitochondrial Phosphoenolpyruvate Carboxykinase (PCK2) Maintains the Function of Bone Marrow Mesenchymal Stromal/stem Cells to Rescue Osteoporotic Phenotype Partly Through Autophagy Dependent Manner
}

\section{Zheng Li}

Peking University School and Hospital of Stomatology: Peking University School of Stomatology https://orcid.org/0000-0003-0215-4401

\section{Xuenan Liu}

Peking University - School of stomatology

\section{Xuejiao Liu}

Peking University - School of Stomatology: Peking University School of Stomatology

\section{Yangge Du}

Peking University - School of Stomatology: Peking University School of Stomatology

\section{Yuan Zhu}

Peking University School and Hospital of Stomatology: Peking University School of Stomatology

\section{Longwei Lv}

Peking University - School of Stomatology: Peking University School of Stomatology

\section{Xiao Zhang}

Peking University School and Hospital of Stomatology: Peking University School of Stomatology

\section{Yunsong Liu}

Peking University - School of Stomatology: Peking University School of Stomatology

Ping Zhang ( $\sim$ zhangping332@bjmu.edu.cn )

Peking University School and Hospital of Stomatology https://orcid.org/0000-0001-8651-2100

\section{Yongsheng Zhou}

Peking University - School of Stomatology: Peking University School of Stomatology

\section{Research}

Keywords: Mitochondrial phosphoenolpyruvate carboxykinase, bone marrow mesenchymal stromal, stem cells, osteoporosis, autophagy

Posted Date: December 1st, 2020 
DOl: https://doi.org/10.21203/rs.3.rs-115769/v1

License: (c) (1) This work is licensed under a Creative Commons Attribution 4.0 International License. Read Full License 


\section{Abstract}

\section{Background}

Mitochondrial phosphoenolpyruvate carboxykinase (PCK2) is a rate-limiting enzyme that plays critical roles in multiple physiological processes. We unveiled the important role of PCK2 on the regulation of osteogenesis by mesenchymal stromal/stem cells (MSCs) in our previous work. Here we further investigated the roles of PCK2 on regulating adipogenesis of MSCs and its therapeutic effect on osteoporosis.

\section{Methods}

We investigated PCK2 function in adipogenic differentiation of MSCs in vitro through loss-and-gain-offunction experiments. This was followed by heterotopic adipose formation assay in nude mice. In addition, ovariectomized (OVX) and aged mice were used as osteoporotic models to test the effect of PCK2 on osteoporosis. The bone formation and adipocyte accumulation were assessed by micro-CT and histological analysis. The multipotent capacity of control and osteoporotic BMMSCs were evaluated by quantitative real time-polymerase chain reaction (qRT-PCR) and western blot analysis.

Results

PCK2 expression levels were significantly decreased in BMMSCs from OVX and aged mice. Furthermore, PCK2 could inhibit adipogenesis of BMMSCs and thus resisting lipid droplet formation and attenuating bone loss in osteoporotic mice. Mechanistically, we detected that autophagy level was decreased in BMMSCs of osteoporotic mice, while overexpression of PCK2 in vivo could rescued the autophagy activity. We further indicated that PCK2 could reverse osteopenia phenotype and adipose formation in OVX and aged mice partially via autophagy.

\section{Conclusions}

Collectively, we suggested that PCK2 could attenuate bone loss and adipocyte accumulation of BMMSCs in osteoporotic mice through autophagy dependent manner. Our study indicated that PCK2 could be a brand and effective therapeutic target for osteoporosis treatment.

\section{Introduction}

Osteoporosis, which is closely associated with age and sex [1], is a systemic skeletal disease characterized by micro-architectural deterioration of bone tissue and the loss of bone mass, leading to clinical possibility of bone fracture [2]. With the aging of the population, the scope of the problem of agerelated bone loss and osteoporosis will continue to expand [3]. Meanwhile, as the number of postmenopausal women increases, the number of osteoporotic cases will also go up at an alarming rate [4]. Therefore, prevention and treatment of osteoporosis is pivotal in avoiding osteoporotic fractures. 
Osteogenesis is crucial to maintain the integrity and function of the mammalian skeletal system [5]. Bone marrow mesenchymal stromal/stem cells (BMMSCs) are an important type of non-hematopoietic multipotent stem cells that play a vital role in maintaining the homeostasis of bone marrow [6]. Under normal circumstances, the balance of osteogenic differentiation and adipogenic differentiation of MSCs in the bone marrow favors bone formation [7]. Various factors such as menopause and aging could disturb the balanced capacity of the BMMSCs that would lead to the accumulation of a large number of bone marrow adipocytes, and thus resulting in metabolic bone disease such as osteoporosis [8, 9]. For example, increased TNF-a caused by estrogen withdrawal inhibits miR-21 and consequently disturbs lineage commitment of BMMSCs, leading to osteoporosis [10]. Other studies have also showed a similar differentiation favor of adipogenesis overwhelming osteogenesis in BMMSCs from postmenopausal osteoporotic women $[11,12]$. Thus, finding the therapeutic target which regulates osteogenesis and adipogenesis of MSCs may be the pivotal pathway to treat osteoporosis.

Autophagy is self-degradative system in eukaryotic cells that delivers cytoplasmic components including damaged macromolecules and organelles to the lysosome for recycling, which is critical for balancing sources of energy in response to nutrient stress [13]. Recently, studies have revealed the significant role of autophagy in maintenance of bone homeostasis and compromised autophagy was also associated to the skeletal degenerative diseases, such as osteoporosis [14]. Knockdown of Atg7 significantly reduces the osteogenic capability of an osteoblastic cell line in vitro, whereas the deletion of Atg5 in osteoblasts results in decreased bone mass in vivo [15]. Meanwhile, adipose-specific deletion of Atg7 has a unique anti-obesity and insulin sensitization effect in mice [16]. In addition, a study showed that targeted deletion of Atg5 impairs adipogenesis [17]. These studies suggest that autophagy, as a vital link in the chain of energy metabolism, has a profound impact on the osteogenesis and adipogenesis. Under conditions of nutrient-deprivation environment, gluconeogenesis is the primary source for endogenous glucose production [10]. Phosphoenolpyruvate carboxykinase (PEPCK) is an important enzyme in gluconeogenesis that catalyzes the decarboxylation of oxaloacetate (OAA) to phosphoenolpyruvate (PEP) in the tricarboxylic acid (TCA) cycle. Our previous study has revealed that the mitochondrial isoform-PCK2 modulates osteogenic differentiation through autophagy-dependent signal pathway [18]. However, whether PCK2 could be the potential target of osteoporosis treatment is unknown. Since the excessive adipogenic differentiation of MSCs can be seen in osteoporosis [9], we also wonder whether regulation of PCK2 could affect the adipogenic capability of BMMSCs.

In the current study, we exhibited that PCK2 could rescue bone loss and inhibit the adipose formation of BMMSCs from estrogen-deficiency and aged-induced osteoporotic mice. Mechanistically, PCK2 may modulate impaired bone regenerative function of endogenous BMMSCs at least partly through autophagy. Our findings uncovered PCK2 is a new and effective therapeutic target for osteoporosis.

\section{Methods}

\section{Culture of human BMMSCs}


The human bone marrow mesenchymal stromal/stem cells (hBMMSCs) used in this work were obtained from ScienCell Research Laboratory (Carlsbad, CA, USA), which were between three and five passages and obtained from three random healthy adult donors. All materials utilized in cell culture were bought from Sigma-Aldrich (St. Louis, MO, USA). Fetal bovine serum (FBS) $(10 \%, \mathrm{v} / \mathrm{v})$, penicillin G $\left(100 \mathrm{U} \cdot \mathrm{mL}^{-1}\right)$ and streptomycin (100 $\left.\mathrm{mg} \cdot \mathrm{mL}^{-1}\right)$ were added into Dulbecco's modified Eagle medium (DMEM) making proliferation culture medium (PM). Dexamethasone (100 nM), L-ascorbic acid (200 mM), and $\beta$ glycerophosphate (10 mM) were added into PM, consisting of osteogenic medium (OM). The adipogenic medium (AM) was comprised of a-MEM containing 10 $\mu \mathrm{M}$ insulin, $100 \mathrm{nM}$ dexamethasone, $200 \mu \mathrm{M}$

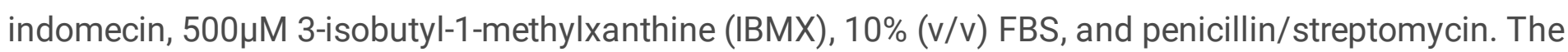
cell culture conditions were $95 \%$ air, $5 \% \mathrm{CO}_{2}, 100 \%$ relative humidity, and $37^{\circ} \mathrm{C}$.

\section{Lentiviral transfection}

Lentiviral transfection was performed as previously described [19]. Lentivirus targeting PCK2 (sh-PCK2) and negative control vector (NC) were purchased from GenePharma Co. (Suzhou, China). Lentiviruses containing PCK2 and the scramble control (vector) were purchased from Vector Builder Co. (Guangzhou, China). Multiplicity of infection (MOI) of 100 was found to be appropriate for transfection. When BMMSCs were exposed to the viral suspension, $5 \mathrm{mg} / \mathrm{ml}$ polybrene (Sigma) was added into the culture medium. After $72 \mathrm{~h}-96 \mathrm{~h}$, cells were incubated with puromycin $(1 \mu \mathrm{g} / \mathrm{ml}$, Sigma-Aldrich) at least for 7 days.

\section{Oil Red 0 Staining}

Cells were cultured in PM and AM separately, and Oil red $\mathrm{O}$ staining and quantitative measurement were carried out on 21-day after adipogenic induction. Briefly, cells were fixed with $10 \%$ formalin for 1 hour and rinsed with $60 \%$ isopropanol, and $0.3 \%$ Oil red 0 working solution was performed. Cells were then washed with distilled water for 3 times. Then these plates were observed, and photographed under the microscope. For quantitative assessment, cells were eluted $100 \%$ isopropanol with $100 \%$ isopropyl alcohol and measured by the spectrophotometric absorbance at $520 \mathrm{~nm}$ against a blank well, which was $100 \%$ isopropyl alcohol.

\section{RNA collection and quantitative reverse transcription polymerase chain reaction (qRT-PCR)}

Cells were seeded in six-well plates, and total cellular RNA was extracted after 7 and 14 days of osteogenic induction. Quantitative real-time PCR was conducted as described previously [20]. The expression of glyceraldehyde 3-phosphate dehydrogenase (GAPDH) was detected for normalization of gene expression. The primers sequences used in this study were listed in additional file 1: Table S1. The $2^{-\Delta \Delta \mathrm{Ct}}$ method was used to calculated the cycle threshold values (Ct values), and the fold differences in relative expression were assessed.

\section{Western blot analysis}


The total protein of cells was prepared in radioimmunoprecipitation assay (RIPA) buffer including protease inhibitor mixture (Roche Applied Science, Mannheim, Germany) and phosphatase inhibitors (Keygenbio China, kgp602). Then the lysates were collected and centrifuged at $14000 \mathrm{rpm}$ at $4{ }^{\circ} \mathrm{C}$ for 15 min. The protein concentration was measured by using Pierce BCA protein assay kit (Thermo Scientific). Equal amount of the protein extracts was separated on proper SDS PAGE $(7.5 \%, 10 \%$ or $15 \%)$ and transferred to polyvinylidene difluoride membrane (Biorad). After blocking in $5 \%$ milk for $2 \mathrm{~h}$, the membranes incubated with the primary antibodies at $4{ }^{\circ} \mathrm{C}$ overnight. The ECL kit (CWBIO) was used to detect the protein bands after incubation with secondary antibodies at room temperature for $1 \mathrm{~h}$. The following antibodies were used and diluted 1:1000. Cell Signaling Technology: PCK2 (\#8565), LC3B (\#2775), RUNX2 (\#12556), PPAR-y囚\#2443区. Huaxingbochuang biotechnology囚 GAPDH (HX1832).

\section{In vivo implantation of BMMSCs and heterotopic adipose tissue formation.}

This study was approved by the Institutional Animal Care and Use Committee of the Peking University Health Science Center (LA2016305). All animal experiments mentioned were conducted in accordance with the Institutional Animal Guidelines. The mice used in this study were bought from Vital River Corporation (Beijing, China). They were kept alive in a pathogen-free facility on a 12-hour light/dark cycle with enough water and food provided ad libitum.

6-week-old ( $n=28$ ) female BALB/C homozygous nude mice were used for heterotopic adipose tissue formation. The 28 mice were randomly divided into four groups (NC, sh-PCK2, vector and PCK2). BMMSCs obtained from these mice were cultured with AM for 7 days. The four group of BMMSCs were incubated with a collagen sponge (Wuxi Biot Bioengineering Institute, Wuxi, China) $(8 \mathrm{~mm} \times 8 \mathrm{~mm} \times 2 \mathrm{~mm}$ ) at $37^{\circ} \mathrm{C}$ for 2 hours, and then implanted them separately into the subcutaneous backside of nude mice. The implants were collected after 6 weeks and fixed with $4 \%$ paraformaldehyde. After that, each sample was cut in half for $\mathrm{H} \& \mathrm{E}$ staining and Oil red $\mathrm{O}$ staining. The specific procedure for nude mouse implantation has been previously described [21-24].

\section{Establishment of estrogen deficiency-induced osteoporosis mice}

8-week-old $(n=60)$ female Balb/c mice were randomly and evenly divided into SHAM and OVX groups. 1\% Pentobarbital sodium $(50 \mathrm{mg} / \mathrm{kg}$ ) was used for general anesthesia by intraperitoneal injection. After general anesthesia, the mice in the SHAM group were performed to resection of some fat tissue close to the ovaries and mice in the OVX group underwent bilateral ovariectomy. 12 weeks later, femurs of mice were collected after sacrifice for Micro-CT scanning to confirm that the estrogen deficiency-induced osteoporosis mice models were successfully established. OVX or SHAM operations were performed on each mouse following standard procedure [23].

\section{Purified PCK2 lentivirus treatment in mice.}

Purified PCK2 overexpression lentivirus (PCK2 lentivirus, Vector Builder Co., Guangzhou, China) was used to overexpress PCK2 in vivo. Purified PCK2 lentivirus $\left(1 \times 10^{9} \mathrm{GC}\right)$ or control virus (vector, $1 \times 10^{9} \mathrm{GC}$ ) were 
tail-injected into the SHAM/OVX/6-week/18-mouth mice twice a week for up to 4 weeks $[25,26]$. After the four-week treatment, mice were sacrificed immediately for histological assessments and BMMSCs isolation.

\section{Isolation of primary mBMMSCs}

The bone marrow was flushed out of mouse femurs and harvested as previously reported in our work [26]. After centrifugation for $5 \mathrm{~min}$ at $1200 \mathrm{rpm}$, the cells were collected and cultured in fresh a-MEM mixed with $20 \%$ FBS and $1 \%$ antibiotics. Non-adherent cells were discarded at $48 \mathrm{~h}$ and attached cells were maintained until they reached full confluency. The proliferation medium was changed on the third day and non-adherent cells were washed out with PBS. The adherent cells were cultured with fresh medium for another 6-8 days with medium changed every two days until they were confluent. Mouse BMSCs (mBMMSCs) were passaged after digestion with $0.25 \%$ trypsin to passage one. The mBMMSCs at passage one were used for the majority of tests in our study. Osteogenic media [fresh a-MEM containing 100nM dexamethasone (Sigma-Aldrich, St. Louis, MO, USA), 0.2mM ascorbic acid (Sigma-Aldrich), and $10 \mathrm{mM} \beta$-glycerophosphate (Sigma-Aldrich)] was used for osteo-induction of mBMMSCs. Adipogenic medium [fresh a-MEM containing10 $\mu \mathrm{M}$ insulin, $100 \mathrm{nM}$ dexamethasone, $200 \mu \mathrm{M}$ indomecin, 500 $\mu \mathrm{M} 3-$ isobutyl-1-methylxanthine (IBMX), 10\% (v/v) FBS, and penicillin/streptomycin] was used for adipoinduction of mBMMSCs.

\section{Analysis of serum biomarker}

For detection of biochemical markers of bone turnover, blood samples were acquired from the heart upon euthanasia. Serum was separated stored and stored at $-80^{\circ} \mathrm{C}$. Serum levels of procollagen $1 \mathrm{~N}$-terminal peptide (P1NP) and bone alkaline phosphatase (ALP) were used as marker of bone formation; tartrateresistant acid phosphatase-5b (TRAP-5b) and type I collagen C-terminal peptide (CTX1) were used as indicator of bone loss [27]. These experiments were applied with the relevant enzyme linked immunoassay (ELISA) kits (IDS, Frankfurt, Germany) according to the manufacturer's instructions.

\section{Histology}

To assess the condition of trabecular bone and bone marrow areas, femurs were fixed in 4\% PFA, decalcified with 5\% EDTA (pH 7.4), and embedded in paraffin. For histological analysis, sections were deparaffinized and stained with hematoxylin and eosin (H\&E). The trabecular bone area percentage was then calculated using NIH ImageJ software.

\section{Micro-computed tomography and bone morphometric analysis of mice}

To evaluate the mass and microarchitecture in bone among the different groups, micro-computed tomography (micro CT) was undertaken using an Inveon MM system (Siemens, Munich, Germany). Images were acquired at an effective pixel size of $8.82 \mu \mathrm{m}$, voltage of $80 \mathrm{kV}$, current of $500 \mu \mathrm{A}$ and exposure time of $1,500 \mathrm{~ms}$ in each of the 360 rotational steps. Parameters were calculated using an Inveon Research Workplace (Siemens) as follows: percentage of bone volume/total volume (BV/TV\%), 
trabecular thickness (Tb.Th), trabecular separation (Tb.Sp) and bone mineral density (BMD) in the trabecular region [in the region of interest ( 0.5 to $1 \mathrm{~mm}$ distal to the proximal epiphysis)] according to guidelines set by the American Society for Bone and Mineral Research [28].

\section{Statistical analysis}

SPSS Statistics 20.0 software (IBM, Armonk, NY) was utilized for statistical analysis. The results are presented as a summary of the mean of three independent experiments and data was indicated as mean \pm standard deviation (SD). For comparisons between two experimental groups, Student's t-test was used. A two-tailed $P$-value $\leq 0.05$ was considered to indicate statistical significance.

\section{Results}

\section{PCK2 was a potential target for osteoporosis treatment}

Ovariectomized (OVX) mice are typically used as an osteoporotic model to induce bone loss and aging

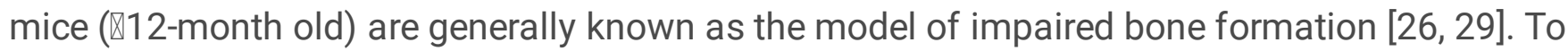
investigate the possible functional significance of PCK2 in bone remodeling in vivo, we first established OVX mice and aged mice (18-month old, $18 \mathrm{~m}$ ) to examine the PCK2 status in osteoporotic mice BMMSCs. As shown in Fig. 1a, microcomputed tomography (micro-CT) analysis and hematoxylin and eosin staining (H\&E staining) exhibited that the trabecular area in femurs were significantly reduced in the OVX group compared to those in the SHAM group at 12 weeks after operation. Moreover, in the OVX group, there was a dramatic decrease in BMD, BV/TV\%, Tb.Th and an increase in Tb.Sp compared with the SHAM mice (additional file 4: Figure. S1a-d). H\&E staining and quantification also showed an increased trend of adipose formation in the bone marrow of femurs of the OVX mice (Fig. 1b-d). Next, BMMSCs were isolated from mouse bone marrow by the traditional flush method [26]. As shown in additional file 4: Figure. S1e, f and Fig. 1e, f, BMMSCs from OVX mice showed impaired osteogenic ability and enhanced adipogenic capacity based on qRT-PCR and western blotting analysis. We then checked the mRNA and protein expression of PCK2 in BMMSCs derived from OVX mice. PCK2 expression levels were decreased in BMMSCs from OVX mice, which were consistently correlated with the RUNX2 levels and reversely correlated with the PPARy levels (Fig.1e, f, additional file 4: Figure S1g).

Similarly, the results of the micro-CT scanning and H\&E staining showed a massive loss of trabecular bone in aged mice (Fig.1 g, h). An increase in the parameters of BMD, BV/TV\%, trabecular thickness and a reduction in trabecular separation (additional file 4: Figure. S1h-k) were observed in the aged mice compared with young mice (6-week, 6w). In aged mice, H\&E staining showed incremental adipose accumulation (Fig. 1h). Specifically, we observed an increase in adipocyte quantity (Fig. 1i) and adipocyte area/tissue (Fig. 1j). The mRNA and protein expression of PPAR-y were significantly upregulated in aged mice, and that of RUNX2 were significantly reduced in aged mice, which exhibited the enhanced adipogenic capacity and the impaired osteogenic capacity (additional file 4: Figure S1I, m, Fig. 1k, I). Analysis of the PCK2 mRNA and protein expression levels in aged mice were also decreased (additional file 4: Figure S1n, Fig. 1k, I). 


\section{PCK2 inhibits adipogenic differentiation of MSCs in vitro}

Our previous work revealed that PCK2 is a positive regulator in osteogenic differentiation of MSCs [18]. To further explore the role of PCK2 in regulating adipogenesis, we next constructed stable PCK2 knockdown or overexpression cells and the lentivirus transfection efficiency was evaluated, as described in our previous article [18]. Oil Red $O$ staining and quantification showed that the number of lipid droplets grew in PCK2-knockdown group (Fig. 2a). The mRNA and protein expression of the adipocyte-specific factors was significantly upregulated by the knockdown of PCK2 (Fig. 2b). Overexpression of PCK2 resulted in a reduction in the number of lipid droplets as determined by oil Red $O$ staining and quantification (Fig. 2c). Moreover, PCK2 overexpressing cells inhibited mRNA expression of adipogenic markers after 14 days of adipogenic induction (Fig. 2 d).

\section{PCK2 suppressed adipogenic differentiation of BMMSCs in vivo}

Since the in vitro results suggested that PCK2 exerts a vital regulatory effect on adipogenesis, we next explored whether PCK2 plays an important role in adipose formation in vivo. We combined four BMMSCs groups (NC, sh-PCK2, vector and PCK2) with a collagen sponge, and then implanted them separately into the subcutaneous backside of nude mice. The complexes were harvested after implantation for 6 weeks. Both H\&E and Oil Red $\mathrm{O}$ staining results revealed more lipid droplets in the PCK2 knockdown group, and fewer adipose tissue-like structures in the PCK2 overexpression group (Fig. 2e, f). Collectively, these data suggested that PCK2 is a negative regulator of the adipogenic capacity of MSCs both in vitro and in vivo.

\section{Lentivirus-mediated PCK2 overexpression reverses osteopenia phenotype and adipose formation in OVX and aged mice partially via autophagy}

Primary osteoporosis, which mainly includes postmenopausal and senile osteoporosis, is the most common type of osteoporosis [30]. These factors containing of age and the estrogen depletion would bring changes to the microenvironment of the bone marrow cavity, which can lead to increase of adipose formation and inhibition of bone formation [31]. We observed that PCK2 could promote osteogenic differentiation of MSCs previously [18] and indicated that PCK2 could suppress the adipogenic differentiation of MSCs in this study, so we further determined the effect of lentivirus-mediated PCK2 overexpression on osteoporosis of mice caused by OVX and aging. Our previous work showed that PCK2 regulates osteogenic differentiation of MSCs through AMPK/ULK1-dependent autophagy [18], giving us the clue to explore the role of autophagy in the regulation of PCK2 reversing the bone loss of osteoporotic mice. To mimic the deficient autophagy activity and investigate whether PCK2 reverses bone loss and adipocyte formation in OVX and aged mice via modulating autophagy, the class III PI3K inhibitor, 3methyladenine (3-MA) $(10 \mathrm{mg} / \mathrm{kg})$ [32] was used to administration.

In our study, sixty 6-week-old female mice were divided into six groups of 10 mice: sham mice with veilinjection of vector (SHAM+vector), sham mice with veil-injection of purified PCK2 lentivirus (SHAM+PCK2), sham mice with veil-injection of purified PCK2 lentivirus and 3-MA (SHAM+PCK2+3-MA), OVX mice with veil-injection of vector (OVX+vector), OVX mice with veil-injection of purified PCK2 
lentivirus (OVX+PCK2) and OVX mice with veil-injection of purified PCK2 lentivirus and 3-MA (OVX+PCK2+3-MA). No significant difference was found between three groups of SHAM mice in micro-CT and H\&E staining of the femurs, whereas PCK2 treatment partially blocked trabecular bone loss in the OVX mice. However, the treatment of 3-MA partly reversed this effect (Fig. 3a, b). Bone histomorphometry analysis showed that the values of BMD, BV/TV\%, and Tb.Th were increased following PCK2 injection, and the Tb.Sp was decreased (Fig. 3c, additional file 2: Table S2). Meanwhile, compared to OVX+PCK2 group, the treatment of 3-MA had adverse effects on bone mass, resulting in a decrease on related parameters in OVX+PCK2+3-MA group (Fig. 3a-C). Moreover, the injection of PCK2 purified lentivirus increased the bone formation markers P1NP and ALP in the serum of OVX mice, whereas decreased the serological level of the bone resorption markers CTX1 and TRAP-5b in OVX group (Fig. 3d). But the treatment of 3-MA partly suppressed these effects triggered by PCK2 (Fig. 3d). To evaluate adipogenesis in bone marrow cavity, we also carried out H\&E staining and observed that PCK2 decreased lipid droplets in bone marrow of OVX mice, whereas 3-MA treatment partially reversed this effect (Fig. 4a). The adipocyte quantity (Fig. 4b) and adipocyte area/tissue area (Fig. 4c) demonstrated the same trend.

In aged group, thirty 6-week-old female mice (6w) and thirty 18-month-old female mice $(18 \mathrm{~m})$ were divided into six groups of 10 mice: $6 w+v e c t o r, 6 w+P C K 2,6 w+P C K 2+3-M A, 18 m+v e c t o r, 18 m+P C K 2$, and $18 m+P C K 2+3-M A$. The results of micro-CT and H\&E staining indicated that PCK2 improved trabecular bone loss of OVX mice, whereas 3-MA treatment partially inhibited this effect (Fig. 5a, b). Specifically, compared with the aged mice treated with vector lentivirus, we observed an increase in bone volume, trabecular thickness, and BMD and a reduction in trabecular separation in the aged mice treated with purified PCK2 lentivirus (Fig. 5c), which were confirmed by bone histomorphometry analysis (additional file 3: Table S3). Furthermore, purified PCK2 lentivirus administration increased the bone formation and resorption markers in serum of aged mice (Fig. $5 \mathrm{~d}$ ). In addition, compared with $18 \mathrm{~m}+\mathrm{vector}$ group, we observed attenuated adipose accumulation in the femurs of $18 m+P C K 2$ group, while 3MA treatment partially blocked this effect (Fig. 6a-c).

Besides, in order to evaluate safety of purified PCK2 lentivirus and the autophagy inhibitor 3-MA used in the present study, we assessed the H\&E staining of mice's vital organs. The results demonstrated no toxicity or inflammatory changes in the kidney, liver, spleen, lung, and heart of the mice (additional file 5-8: Figure S2-5). Altogether, it can be inferred that PCK2 could reverse bone loss and adipose formation in OVX and aged mice at least partially through autophagy.

\section{PCK2 rescues the regenerative properties of endogenous BMMSCs in OVX mice and aged mice through autophagy dependent manner}

Autophagy is a conserved physical process which is essential for cell survival, differentiation, development, and homeostasis [33]. Our previous study suggested that PCK2 regulates osteogenic differentiation of MSCs through modulating autophagy [18]. We further investigated whether PCK2 could rescue the regenerative capability of endogenous BMMSCs in OVX and aged mice through autophagy. 
We harvested BMMSCs from 12 groups, including SHAM+vector, SHAM+PCK2, SHAM+PCK2+3-MA, OVX+vector, OVX+PCK2, and OVX+PCK2+3-MA; 6w+vector, 6w+PCK2, 6w+PCK2+3-MA, 18m+vector, 18m+PCK2, and 18m+PCK2+3-MA. These cells were cultured and exposed to osteogenic/adipogenic induction to determine the differentiation ability and the autophagy level of endogenous BMMSCs from the groups mentioned above. According to the results, qRT-PCR and western blotting analysis revealed that PCK2-overexpression elevated the osteogenic differentiation capacity and suppressed the adipogenic ability of endogenous BMMSCs of OVX mice, while the treatment of 3-MA reversed this effect (Fig. 7a-d). The autophagy level of endogenous BMMSCs in OVX mice was downregulated compared with that in SHAM mice, which was confirmed by the decreased accumulation of microtubule associated protein 1 light chain $3 \beta$ (LC3B, a positive marker of autophagy) (Fig. 7b, d). PCK2-overexpression in OVX mice led to accumulation of LC3B of endogenous BMMSCs compared to control group, but adding 3-MA blocked this trend (Fig. 7b, d). Similarly, upon 3-MA treatment, overexpression of PCK2 failed to elevate osteogenic differentiation capacity of endogenous BMMSCs in aged mice (Fig. 7e, f). The adipogenic differentiation capacity of endogenous BMMSCs in aged mice was enhanced in PCK2 + 3-MA group, compared to PCK2 group (Fig. 7g, h). Meanwhile, the trend of LC3B accumulation in aged mice was similar to that of OVX mice (Fig. 7e-h). Taken together, it could be deduced that PCK2 could restore lineage commitment and autophagy level of endogenous BMMSCs at least partly through autophagy, as well as alleviating osteoporotic phenotype in OVX and aged mice.

\section{Discussion}

Aging and estrogen deficiency after menopause are closely associated with rapid bone loss, osteoporosis, and increased fracture risk [34]. The prevalence of osteoporosis has increased significantly among the elderly as life expectancy has increased in modern society. Currently available strong agents against osteoporosis are bisphosphonates, which trigger osteoclast apoptosis [35], and denosumab, which is an anti-RANKL antibody [36]. However, prolonged use bisphosphonates has been reported to be associated with atypical femoral fractures, which is a bottleneck of this drug [37]. Denosumab is reported to be associated with atypical femoral fractures and osteonecrosis of the jaw. In addition, once going off the drug, it would bring about an imbalance in bone remodeling, leading to a rapid bone loss and an increased risk of fractures [38]. The term of anabolic agents is a new concept which emerged to treat osteoporosis, pertaining to all those medications that can stimulate bone formation and thus may restore bone quality and quantity to a greater extent. Parathyroid hormone (PTH) is a promising potent anabolic agent, promoting bone formation through binding to its type 1 receptor (PTH1R) on the surface of osteoblasts and osteocytes. However, PTH shows a limited anabolic window of no more than 24 months [34]. Moreover, teriparatide, the PTH analog and the most effective agent for osteoporosis treatment, leads to adverse effects on bone resorption [39]. Additionally, side effects of PTH include nausea, headache and dizziness. Transient hypercalcemia and hypercalciuria induced by PTH (1-84) have been indicated [39]. Therefore, identifying novel and promising biological therapeutic targets for osteoporosis treatment is of great importance. In our study, we noticed that PCK2 expression level was increased 
during MSCs osteogenic differentiation [18] and decreased in BMMSCs from OVX and aged mice, suggesting that PCK2 may play a potential role in the pathogenesis of osteoporosis.

Autophagy functions to degrade and recycle damaged proteins and organelles for cell homeostasis. In recent years, autophagy has been gradually identified as a crucial process taking part in the self-renewal, pluripotency, development, differentiation and quiescence of stem cells [40]. It has been reported impairment of autophagy is associated with osteoporosis [41]. In vitro studies indicated that pharmacological inhibition of autophagy in osteoblast-like cells increases oxidative stress and stimulates apoptosis in these cells. To the contrary, induction of autophagy in cultures of osteoblast-like cells reduces their oxidative stress and inhibits apoptosis. It has also been reported that estrogen inhibits osteoblast apoptosis in vitro, inducing autophagy in these cells [42]. In vivo studies also showed that pharmacological inhibition with chloroquine and genetic inhibition by conditional knockout of the Atg7 gene in monocytes resulted in a dramatically decrease of bone loss in animal models [43]. These preclinical in vivo and in vitro studies indicate a close relationship between the dysregulation of the autophagy and osteoporosis. A genetic screening study using genome-wide association studies (GWASs) in human revealed the potential role of the regulation-of-autophagy in human wrist BMD variation and osteoporosis [44]. Since osteoporosis became a serious public health problem with an increased incidence rate in the next decades, understanding the cellular and molecular mechanisms between autophagy and osteoporosis is crucial and paramount for the development of new therapy strategies. Our previous work showed that PCK2 regulates osteogenic differentiation of MSCs through AMPK/ULK1dependent autophagy [18], prompting us to explore the role of autophagy in the mechanism of PCK2 reversing the bone loss of osteoporotic mice. Similar to a recent study, which showed that impaired autophagy is associated with abnormal lineage differentiation of OVX BMMSCs [14], we noticed lower autophagy activity in BMMSCs of osteoporotic mice, which was shown by decreased LC3B accumulation in OVX and aged mice in this study (Fig. 7). These results indicated that factors modulating autophagy may be potential targets for osteoporosis treatment.

There are still some questions that need to be further studied. For example, according to our data, the rescuing effect of PCK2 in SHAM mice and 6w mice was not that obvious, compared to the significant role in OVX mice and $18 \mathrm{~m}$ mice. The possible reason maybe that in bone marrow, there is a negative feedback mechanism which inhibiting the imbalance of hormones or enzymes, and thus maintaining the homeostasis of the system. In addition, it was reported that autophagy is associated with lipid turnover to some extent, and 3-MA was indicated to play a role on adipocyte lipolysis [45]. Thus, we need to further rule out this interference from the adipogenesis effect of 3-MA. A study has reported that the change of apoptosis induced by interfered autophagy was too subtle to affect numbers of BMMSCs in vitro, which suggested that restoration of bone mass possibly attributed to BMMSCs with recovered function rather than more BMMSCs in osteoporotic mice [14]. These results remind us of the possible function of apoptosis in modulating BMMSCs and subsequent effect on bone mass, and thus need to be further studied. 


\section{Conclusions}

In the current study, we revealed the unreported application of PCK2 in treatment for osteoporosis. Besides of acting as a potent regulator promoting the osteogenic capacity of MSCs reported in our previous work [18], PCK2 is also a critical modulator to inhibit the adipogenic differentiation of MSCs. Injection of purified lentivirus to overexpress PCK2 could rescue the bone loss and inhibit adipocyte accumulation in OVX and aging mice, while treatment of 3-MA (which is an inhibitor for autophagy) reversed this effect. Mechanistically, PCK2 may rescue the damaged regenerative capacity of endogenous BMMSCs in estrogen-deficiency and aging mice at least partly through autophagy. Taken together, our study demonstrated that PCK2 could be a novel therapeutic target for metabolic bone diseases.

\section{Abbreviations}

ALP: alkaline phosphatase; AM: adipogenic medium; AMPK: AMP-activated protein kinase; ATG7: autophagy related 7; BMD: Bone mineral density; BMMSCs: Bone marrow mesenchymal/stromal stem cells; BV/TV: Trabecular bone volume/tissue volume; CTX1: type I collagen C-terminal peptide; DMEM: Dulbecco's modified Eagle medium; ELISA: Enzyme-linked immunosorbent assay; FBS: fetal bovine serum; GAPDH: glyceraldehyde 3-phosphate dehydrogenase; H\&E: hematoxylin and eosin; LC3B: Microtubule associated protein 1 light chain 3 ;; NC: negative control; PEP: phosphoenolpyruvate; PCK2: mitochondrial phosphoenolpyruvate carboxykinase; PM: proliferation culture medium; OM: osteogenic medium; P1NP: Procollagen I N-terminal propeptide; RUNX2: Runt-related transcription factor 2; SD: standard deviation; 3-MA: 3-methyladenine; TARP-5b: tartrate-resistant acid phosphatase-5b; Tb.Sp: Trabecular spacing; Tb.Th: Trabecular thickness ULK1: unc-51 like kinase 1; vector: scramble control.

\section{Declarations}

\section{Acknowledgements}

The authors are grateful to Dr. Xuejiao Liu and Dr. Chunhui Sheng for the help in animal operations.

Authors' contributions Zheng Li was responsible for the conception and design, collection and/or assembly of data, data analyses and interpretation, and manuscript writing. Xuenan Liu, Xuejiao Liu, Yuan Zhu and Yangge Du were responsible for the collection and/or assembly of data, Longwei Lv, Xiao Zhang and Yunsong Liu was responsible for the data analyses and interpretation in the animal experiments. Ping Zhang was responsible for the conception and design, financial support, data analyses and interpretation, and manuscript writing. Yongsheng Zhou was responsible for the conception and design, financial support and manuscript writing. All authors read and approved the final manuscript.

\section{Funding}


This work was supported by the National Natural Science Foundation of China under grant 81870742 to Yongsheng Zhou and 81970911 to Ping Zhang; the Beijing Nova Program under grant Z181100006218037 to Ping Zhang; The second batch of Special Funding from China Post-Doctoral Science Foundation (before the station) under grant 2020TQ0020 to Zheng Li.

\section{Availability of data and materials}

The authors confirm that all data underlying the findings are fully available.

\section{Ethics approval and consent to participate}

This study was carried out in strict accordance with the recommendations of the Guide for the Care and Use of Laboratory Animals of the National Institutes of Health. The protocol was approved by the Institutional Animal Care and Use Committee of the Peking University Health Science Center (LA2016305). All surgeries were performed under anesthesia, and all efforts were made to minimize animal suffering.

\section{Consent for publication}

Not applicable.

\section{Competing interests}

The authors declare that they have no competing interests.

\section{Author details}

1 Department of Prosthodontics, School and Hospital of Stomatology, Peking University, 22 Zhongguancun Nandajie, Haidian District, Beijing 100081, China

2 National Engineering Lab for Digital and Material Technology of Stomatology, National Clinical Research Center for Oral Diseases, Peking University School and Hospital of Stomatology, Peking University, 22 Zhongguancun Nandajie, Haidian District, Beijing 100081, China.

\section{References}

[1] Vandenput L., Mellström D., Kindmark A., et al., High Serum SHBG Predicts Incident Vertebral Fractures in Elderly Men, J Bone Miner Res, 2016, 31(3): 683-9.

[2] Khosla S., Bellido T.M., Drezner M.K., et al., Forum on aging and skeletal health: summary of the proceedings of an ASBMR workshop, J Bone Miner Res, 2011, 26(11): 2565-78.

[3] Khosla S., Farr J.N., Kirkland J.L., Inhibiting Cellular Senescence: A New Therapeutic Paradigm for AgeRelated Osteoporosis, J Clin Endocrinol Metab, 2018, 103(4): 1282-1290. 
[4] Shevroja E., Marques-Vidal P., Aubry-Rozier B., et al., Cohort Profile: The OsteoLaus study, Int J Epidemiol, 2019, 48(4): 1046-1047g.

[5] Sacchetti B., Funari A., Remoli C., et al., No Identical "Mesenchymal Stem Cells" at Different Times and Sites: Human Committed Progenitors of Distinct Origin and Differentiation Potential Are Incorporated as Adventitial Cells in Microvessels, Stem Cell Reports, 2016, 6(6): 897-913.

[6] Ankrum J.A., Ong J.F., Karp J.M., Mesenchymal stem cells: immune evasive, not immune privileged, Nat Biotechnol, 2014, 32(3): 252-60.

[7] You L., Pan L., Chen L., et al., MiR-27a is Essential for the Shift from Osteogenic Differentiation to Adipogenic Differentiation of Mesenchymal Stem Cells in Postmenopausal Osteoporosis, Cell Physiol Biochem, 2016, 39(1): 253-65.

[8] Takafuji Y., Tatsumi K., Ishida M., et al., Plasminogen activator inhibitor-1 deficiency suppresses osteoblastic differentiation of mesenchymal stem cells in mice, J Cell Physiol, 2019, 234(6): 9687-9697.

[9] Teotia P.K., Hussein K.E., Park K.M., et al., Mouse adipose tissue-derived adult stem cells expressed osteogenic specific transcripts of osteocalcin and parathyroid hormone receptor during osteogenesis, Transplant Proc, 2013, 45(8): 3102-7.

[10] Yang N., Wang G., Hu C., et al., Tumor necrosis factor a suppresses the mesenchymal stem cell osteogenesis promoter miR-21 in estrogen deficiency-induced osteoporosis, J Bone Miner Res, 2013, 28(3): 559-73.

[11] Donoso O., Pino A.M., Seitz G., et al., Osteoporosis-associated alteration in the signalling status of BMP-2 in human MSCs under adipogenic conditions, J Cell Biochem, 2015, 116(7): 1267-77.

[12] Astudillo P., Ríos S., Pastenes L., et al., Increased adipogenesis of osteoporotic human-mesenchymal stem cells (MSCs) characterizes by impaired leptin action, J Cell Biochem, 2008, 103(4): 1054-65.

[13] Kuma A., Komatsu M., Mizushima N., Autophagy-monitoring and autophagy-deficient mice, Autophagy, 2017, 13(10): 1619-1628.

[14] Qi M., Zhang L., Ma Y., et al., Autophagy Maintains the Function of Bone Marrow Mesenchymal Stem Cells to Prevent Estrogen Deficiency-Induced Osteoporosis, Theranostics, 2017, 7(18): 4498-4516.

[15] Nollet M., Santucci-Darmanin S., Breuil V., et al., Autophagy in osteoblasts is involved in mineralization and bone homeostasis, Autophagy, 2014, 10(11): 1965-77.

[16] Zhang Y., Goldman S., Baerga R., et al., Adipose-specific deletion of autophagy-related gene 7 (atg7) in mice reveals a role in adipogenesis, Proc Natl Acad Sci U S A, 2009, 106(47): 19860-5. 
[17] Baerga R., Zhang Y., Chen P.H., et al., Targeted deletion of autophagy-related 5 (atg5) impairs adipogenesis in a cellular model and in mice, Autophagy, 2009, 5(8): 1118-30.

[18] Li Z., Liu X., Zhu Y., et al., Mitochondrial Phosphoenolpyruvate Carboxykinase Regulates Osteogenic Differentiation by Modulating AMPK/ULK1-Dependent Autophagy, Stem Cells, 2019, 37(12): 1542-1555.

[19] Tao J., Wang H., Zhai Y., et al., Downregulation of Nrf2 promotes autophagy-dependent osteoblastic differentiation of adipose-derived mesenchymal stem cells, Experimental Cell Research, 2016, 349(2): 221-229.

[20] Jia L.F., Wei S.B., Gan Y.H., et al., Expression, regulation and roles of miR-26a and MEG3 in tongue squamous cell carcinoma, Int J Cancer, 2014, 135(10): 2282-93.

[21] Ge W., Liu Y., Chen T., et al., The epigenetic promotion of osteogenic differentiation of human adipose-derived stem cells by the genetic and chemical blockade of histone demethylase LSD1, Biomaterials, 2014, 35(23): 6015-25.

[22] Ge W., Shi L., Zhou Y., et al., Inhibition of osteogenic differentiation of human adipose-derived stromal cells by retinoblastoma binding protein 2 repression of RUNX2-activated transcription, Stem Cells, 2011, 29(7): 1112-25.

[23] Wan Y., Zhuo N., Li Y., et al., Autophagy promotes osteogenic differentiation of human bone marrow mesenchymal stem cell derived from osteoporotic vertebrae, Biochem Biophys Res Commun, 2017, 488(1): 46-52.

[24] Liu X., Li Z., Liu H., et al., Flufenamic Acid Inhibits Adipogenic Differentiation of Mesenchymal Stem Cells by Antagonizing the PI3K/AKT Signaling Pathway, Stem Cells Int, 2020, (2):1-12.

[25] Yang R., Yu T., Kou X., et al., Tet1 and Tet2 maintain mesenchymal stem cell homeostasis via demethylation of the P2rX7 promoter, Nat Commun, 2018, 9(1): 2143.

[26] Min Z., Xiaomeng L., Zheng L., et al., Asymmetrical methyltransferase PRMT3 regulates human mesenchymal stem cell osteogenesis via miR-3648, Cell Death Dis, 2019, 10(8): 581.

[27] Liu H., Li W., Liu Y., et al., Co-administration of aspirin and allogeneic adipose-derived stromal cells attenuates bone loss in ovariectomized rats through the anti-inflammatory and chemotactic abilities of aspirin, Stem Cell Res Ther, 2015, 6(200):1-11.

[28] Bouxsein M.L., Boyd S.K., Christiansen B.A., et al., Guidelines for assessment of bone microstructure in rodents using micro-computed tomography, J Bone Miner Res, 2010, 25(7): 1468-86.

[29] Zhang P., Liu Y., Jin C., et al., Histone H3K9 Acetyltransferase PCAF Is Essential for Osteogenic Differentiation Through Bone Morphogenetic Protein Signaling and May Be Involved in Osteoporosis, Stem Cells, 2016, 34(9): 2332-41. 
[30] Ishii S., Cauley J.A., Greendale G.A., et al., Pleiotropic effects of obesity on fracture risk: the Study of Women's Health Across the Nation, J Bone Miner Res, 2014, 29(12): 2561-70.

[31] Ambrosi T.H., Scialdone A., Graja A., et al., Adipocyte Accumulation in the Bone Marrow during Obesity and Aging Impairs Stem Cell-Based Hematopoietic and Bone Regeneration, Cell Stem Cell, 2017, 20(6): 771-784.e6.

[32] Macias-Ceja D.C., Cosín-Roger J., Ortiz-Masiá D., et al., Stimulation of autophagy prevents intestinal mucosal inflammation and ameliorates murine colitis, Br J Pharmacol, 2017, 174(15): 2501-2511.

[33] Sotthibundhu A., Promjuntuek W., Liu M., et al., Roles of autophagy in controlling stem cell identity: a perspective of self-renewal and differentiation, Cell Tissue Res, 2018, 374(2): 205-216.

[34] Gennari L., Rotatori S., Bianciardi S., et al., Treatment needs and current options for postmenopausal osteoporosis, Expert Opin Pharmacother, 2016, 17(8): 1141-52.

[35] Chotiyarnwong P., McCloskey E.V., Pathogenesis of glucocorticoid-induced osteoporosis and options for treatment, Nat Rev Endocrinol, 2020, 16(8): 437-447.

[36] Fukumoto S., Matsumoto T., Recent advances in the management of osteoporosis, F1000Res, 2017, 9(6):565.

[37] Black D.M., Rosen C.J., Clinical Practice. Postmenopausal Osteoporosis, N Engl J Med, 2016, 374(3): 254-62.

[38] Popp A.W., Zysset P.K., Lippuner K., Rebound-associated vertebral fractures after discontinuation of denosumab-from clinic and biomechanics, Osteoporos Int, 2016, 27(5): 1917-21.

[39] Bandeira L., Bilezikian J.P., Novel Therapies for Postmenopausal Osteoporosis, Endocrinol Metab Clin North Am, 2017, 46(1): 207-219.

[40] Ho T.T., Warr M.R., Adelman E.R., et al., Autophagy maintains the metabolism and function of young and old stem cells, Nature, 2017, 543(7644): 205-210.

[41] Rodolfo C., Di Bartolomeo S., Cecconi F., Autophagy in stem and progenitor cells, Cell Mol Life Sci, 2016, 73(3): 475-96.

[42] Yang Y.H., Li B., Zheng X.F., et al., Oxidative damage to osteoblasts can be alleviated by early autophagy through the endoplasmic reticulum stress pathway-implications for the treatment of osteoporosis, Free Radic Biol Med, 2014, 77:10-20.

[43] Lin N.Y., Chen C.W., Kagwiria R., et al., Inactivation of autophagy ameliorates glucocorticoid-induced and ovariectomy-induced bone loss, Ann Rheum Dis, 2016, 75(6): 1203-10. 
[44] Zhang L., Guo Y.F., Liu Y.Z., et al., Pathway-based genome-wide association analysis identified the importance of regulation-of-autophagy pathway for ultradistal radius BMD, J Bone Miner Res, 2010, 25(7): 1572-80.

[45] Heckmann B.L., Yang X., Zhang X., et al., The autophagic inhibitor 3-methyladenine potently stimulates PKA-dependent lipolysis in adipocytes, Br J Pharmacol, 2013, 168(1): 163-71.

\section{Figures}


fig. 1

a
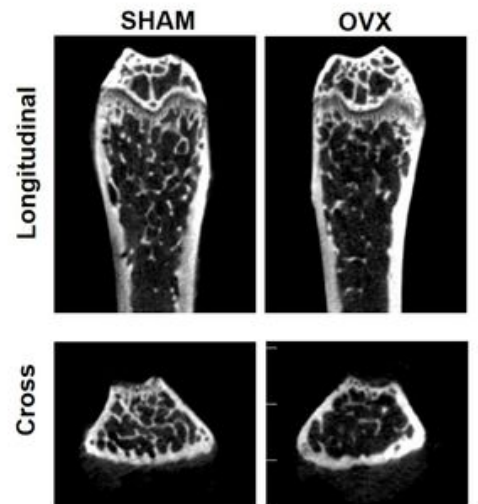

c

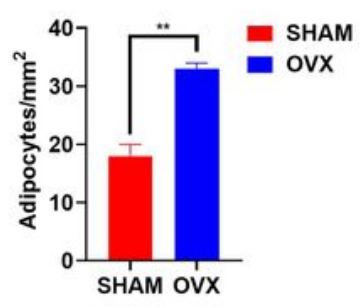

g
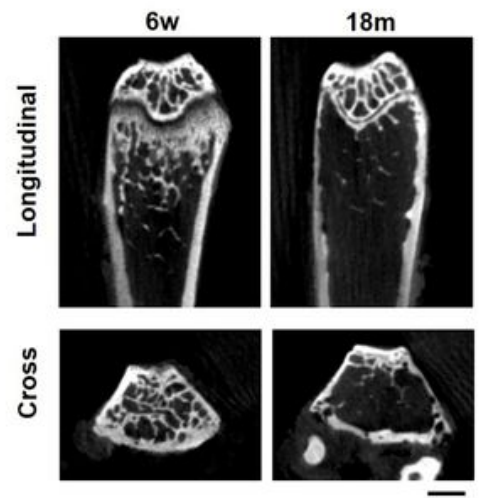

i

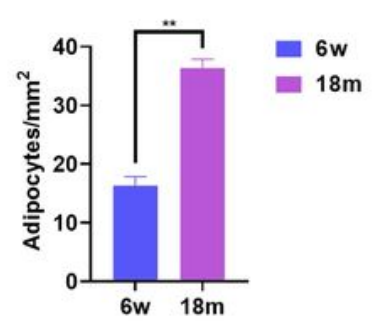

d
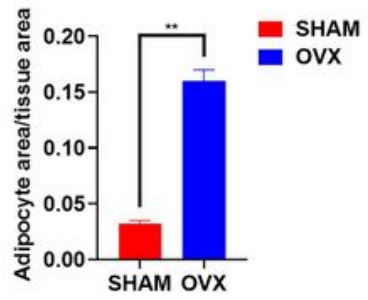

h

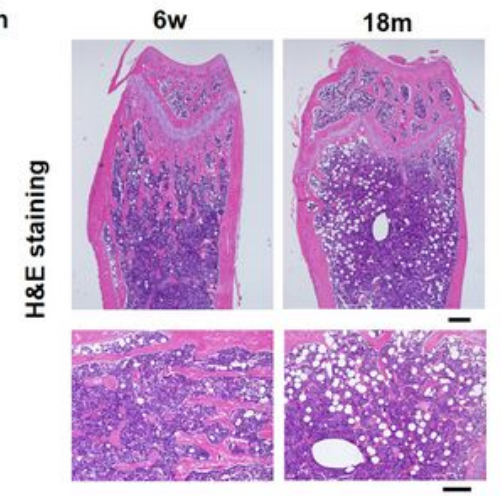

k

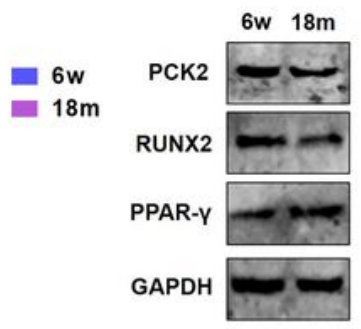

e

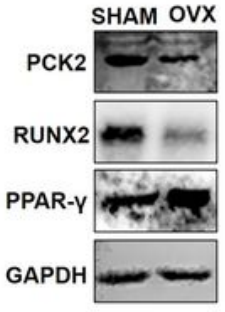

I
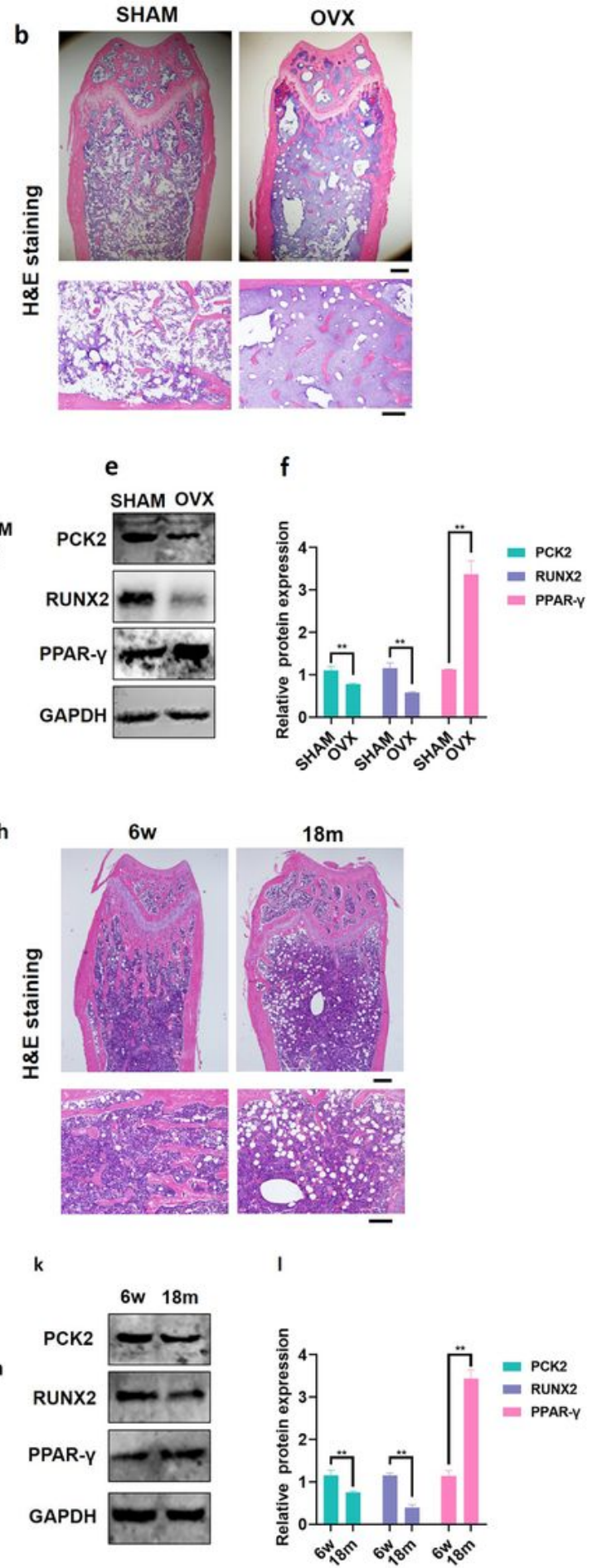

\section{Figure 1}

PCK2 is a potential target for treatment of osteopenia phenotype. $a, b$ Micro-CT image and H\&E staining of OVX mice and SHAM mice. Scale bar for micro-CT image: $1 \mathrm{~mm}$; scale bar for H\&E staining: the upper lane $200 \mu \mathrm{m}$, the lower lane $50 \mu \mathrm{m}$. c, d Adipocyte count and adipocyte area/tissue area based on H\&E staining of femurs in SHAM and OVX mice. e, $f$ PCK2, RUNX2, and PPAR-y protein levels in bone marrowderived MSCs from OVX mice and SHAM mice. Data are shown as mean \pm SD; $n=3$ independent 
experiments; ${ }^{\star \star} \mathrm{P}<0.01 \mathrm{~g}, \mathrm{~h}$ Micro-CT image and H\&E staining of 6-week mice and 18-month mice. Scale bar for micro-CT image: $1 \mathrm{~mm}$; scale bar for H\&E staining: the upper lane $200 \mu \mathrm{m}$, the lower lane $50 \mu \mathrm{m}$. c, d Adipocyte count and adipocyte area/tissue area based on H\&E staining of femurs in $6 \mathrm{w}$ mice and $18 \mathrm{~m}$ mice. e, f PCK2, RUNX2, and PPAR-y protein levels in bone marrow-derived MSCs from 6w mice and 18m mice. Data are shown as mean $\pm S D ; n=3$ independent experiments; $* * P<0.01$.

fig. 1

a

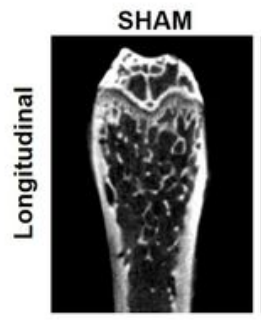

瓷

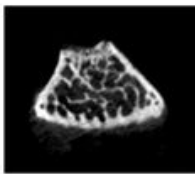

C

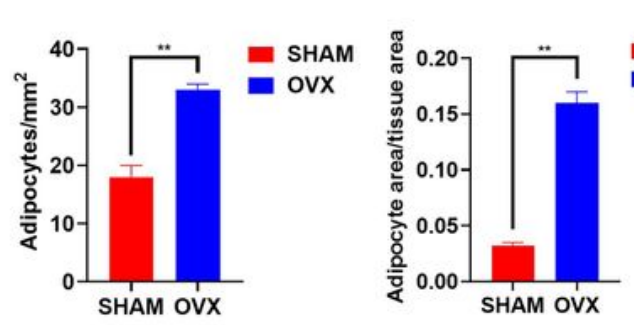

g
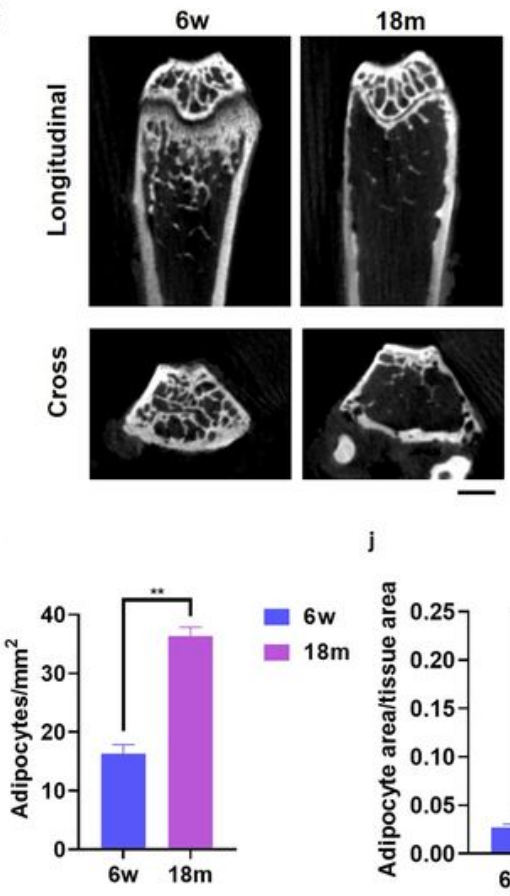
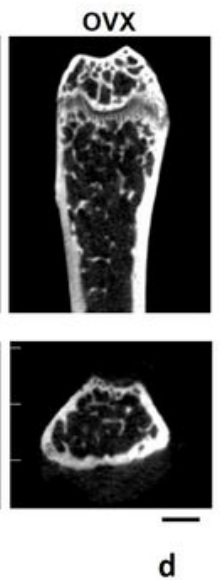

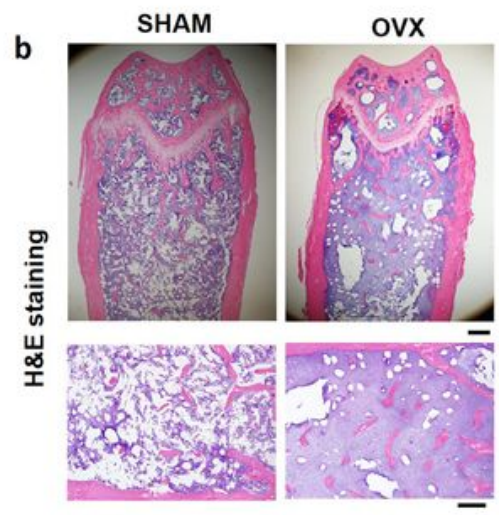

e

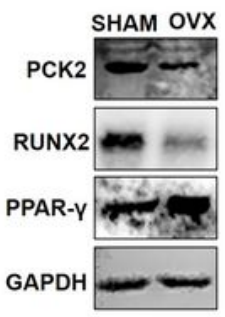

h

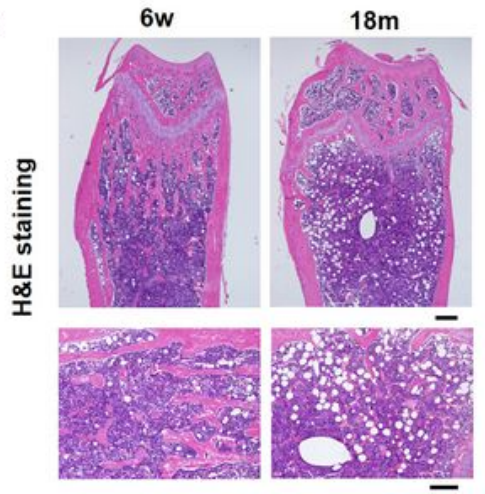

k

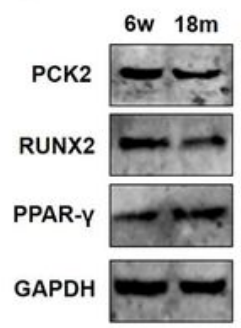

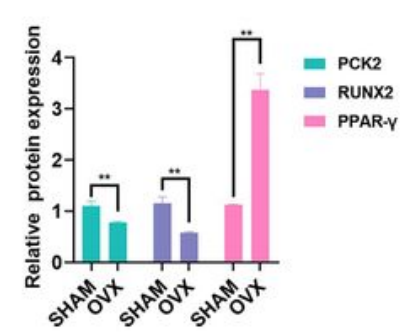

f

I

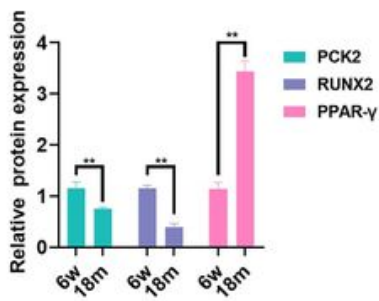

Figure 1 
PCK2 is a potential target for treatment of osteopenia phenotype. a, b Micro-CT image and H\&E staining of OVX mice and SHAM mice. Scale bar for micro-CT image: $1 \mathrm{~mm}$; scale bar for H\&E staining: the upper lane $200 \mu \mathrm{m}$, the lower lane $50 \mu \mathrm{m}$. c, d Adipocyte count and adipocyte area/tissue area based on H\&E staining of femurs in SHAM and OVX mice. e, $f$ PCK2, RUNX2, and PPAR-y protein levels in bone marrowderived MSCs from OVX mice and SHAM mice. Data are shown as mean $\pm S D ; n=3$ independent experiments; ${ }^{* *} \mathrm{P}<0.01 \mathrm{~g}, \mathrm{~h}$ Micro-CT image and H\&E staining of 6-week mice and 18-month mice. Scale bar for micro-CT image: $1 \mathrm{~mm}$; scale bar for H\&E staining: the upper lane $200 \mu \mathrm{m}$, the lower lane $50 \mu \mathrm{m}$. c, d Adipocyte count and adipocyte area/tissue area based on H\&E staining of femurs in $6 \mathrm{w}$ mice and $18 \mathrm{~m}$ mice. e, $f$ PCK2, RUNX2, and PPAR-y protein levels in bone marrow-derived MSCs from $6 \mathrm{w}$ mice and $18 \mathrm{~m}$ mice. Data are shown as mean $\pm S D ; n=3$ independent experiments; $* * P<0.01$. 
fig. 1

a
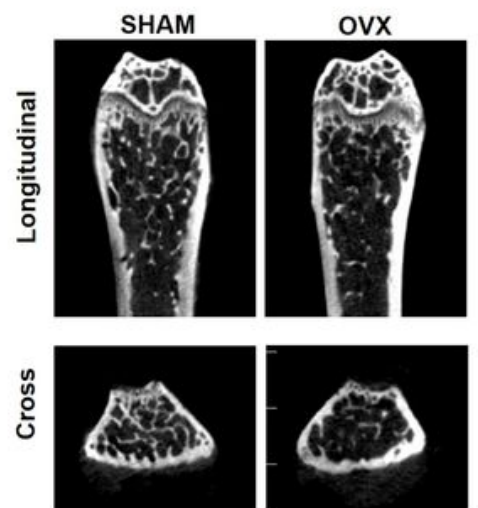

c

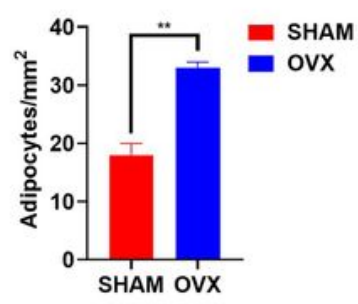

g
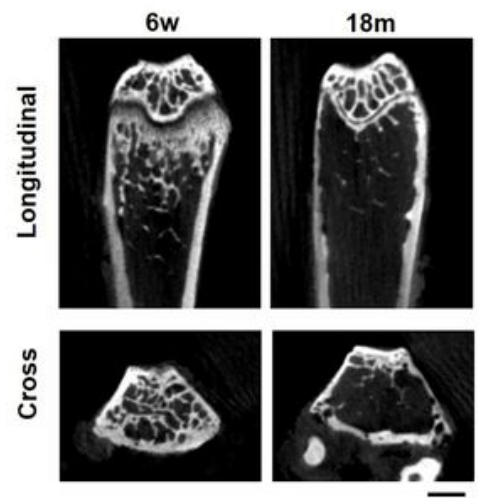

i

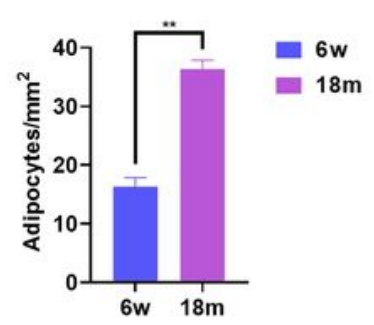

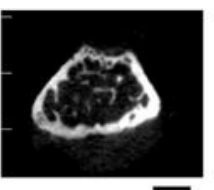

d

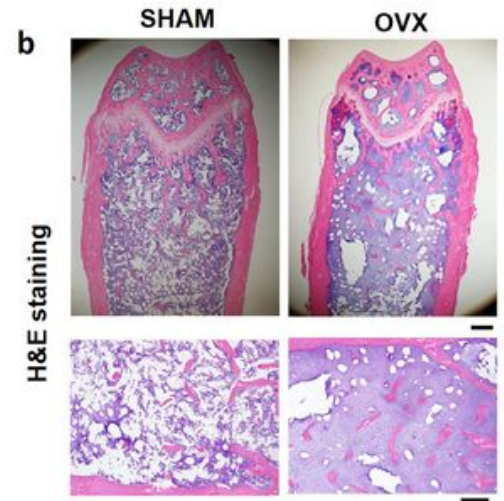

e

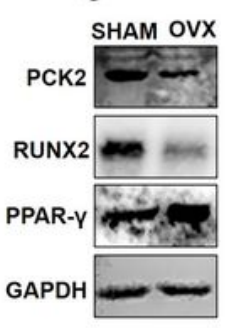

f

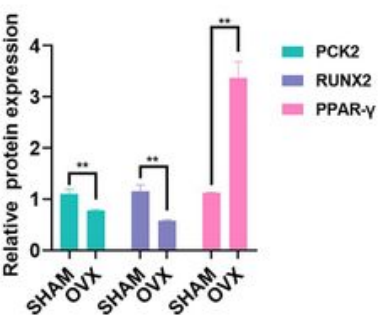

h

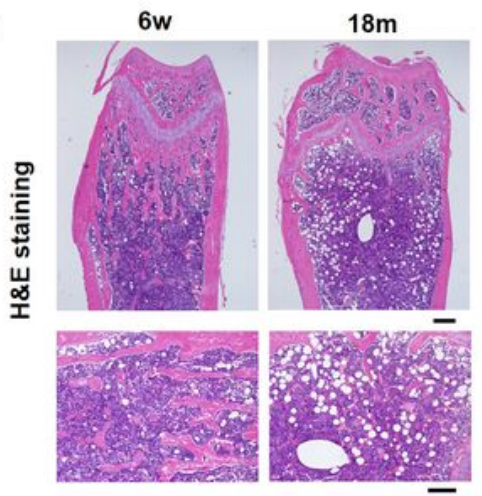

k

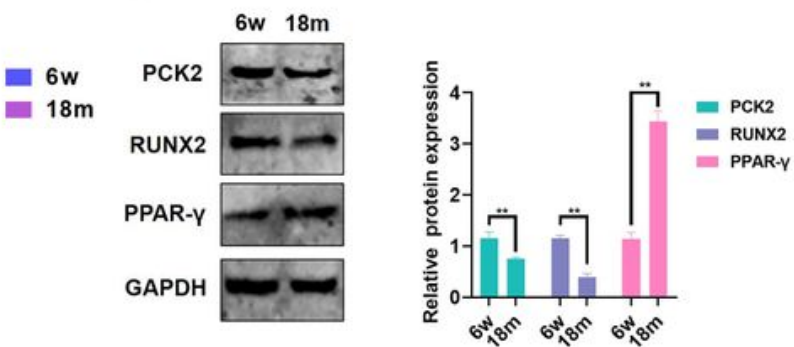

\section{Figure 1}

PCK2 is a potential target for treatment of osteopenia phenotype. $a, b$ Micro-CT image and H\&E staining of OVX mice and SHAM mice. Scale bar for micro-CT image: $1 \mathrm{~mm}$; scale bar for H\&E staining: the upper lane $200 \mu \mathrm{m}$, the lower lane $50 \mu \mathrm{m}$. c, d Adipocyte count and adipocyte area/tissue area based on H\&E staining of femurs in SHAM and OVX mice. e, $f$ PCK2, RUNX2, and PPAR-y protein levels in bone marrowderived MSCs from OVX mice and SHAM mice. Data are shown as mean \pm SD; $n=3$ independent 
experiments; ${ }^{\star \star} \mathrm{P}<0.01 \mathrm{~g}, \mathrm{~h}$ Micro-CT image and H\&E staining of 6-week mice and 18-month mice. Scale bar for micro-CT image: $1 \mathrm{~mm}$; scale bar for H\&E staining: the upper lane $200 \mu \mathrm{m}$, the lower lane $50 \mu \mathrm{m}$. c, d Adipocyte count and adipocyte area/tissue area based on H\&E staining of femurs in $6 \mathrm{w}$ mice and $18 \mathrm{~m}$ mice. e, $f$ PCK2, RUNX2, and PPAR-y protein levels in bone marrow-derived MSCs from 6w mice and 18m mice. Data are shown as mean $\pm S D ; n=3$ independent experiments; $* * P<0.01$.
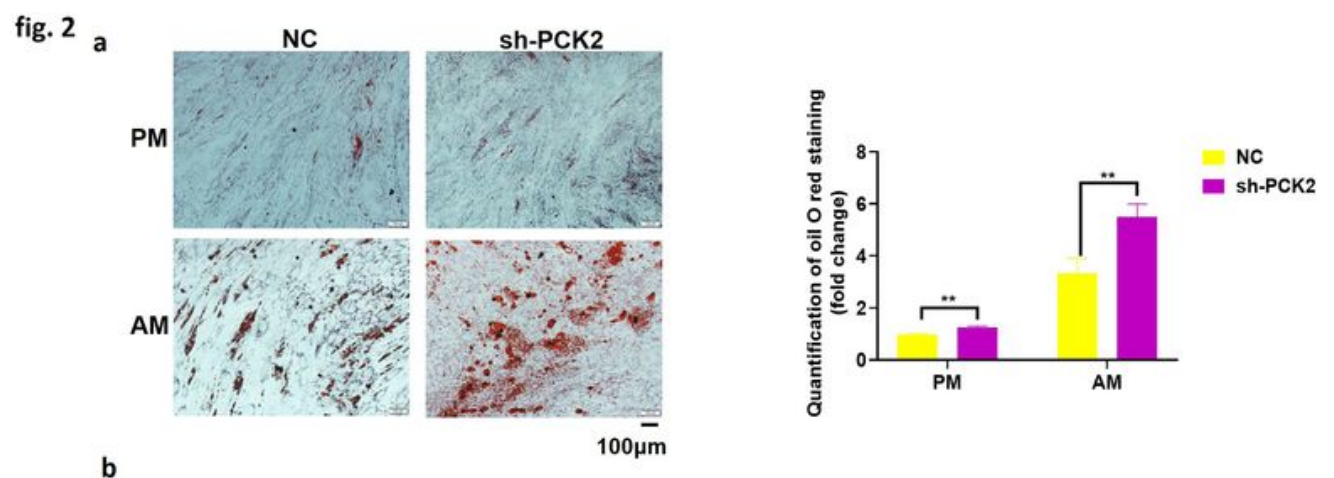

b
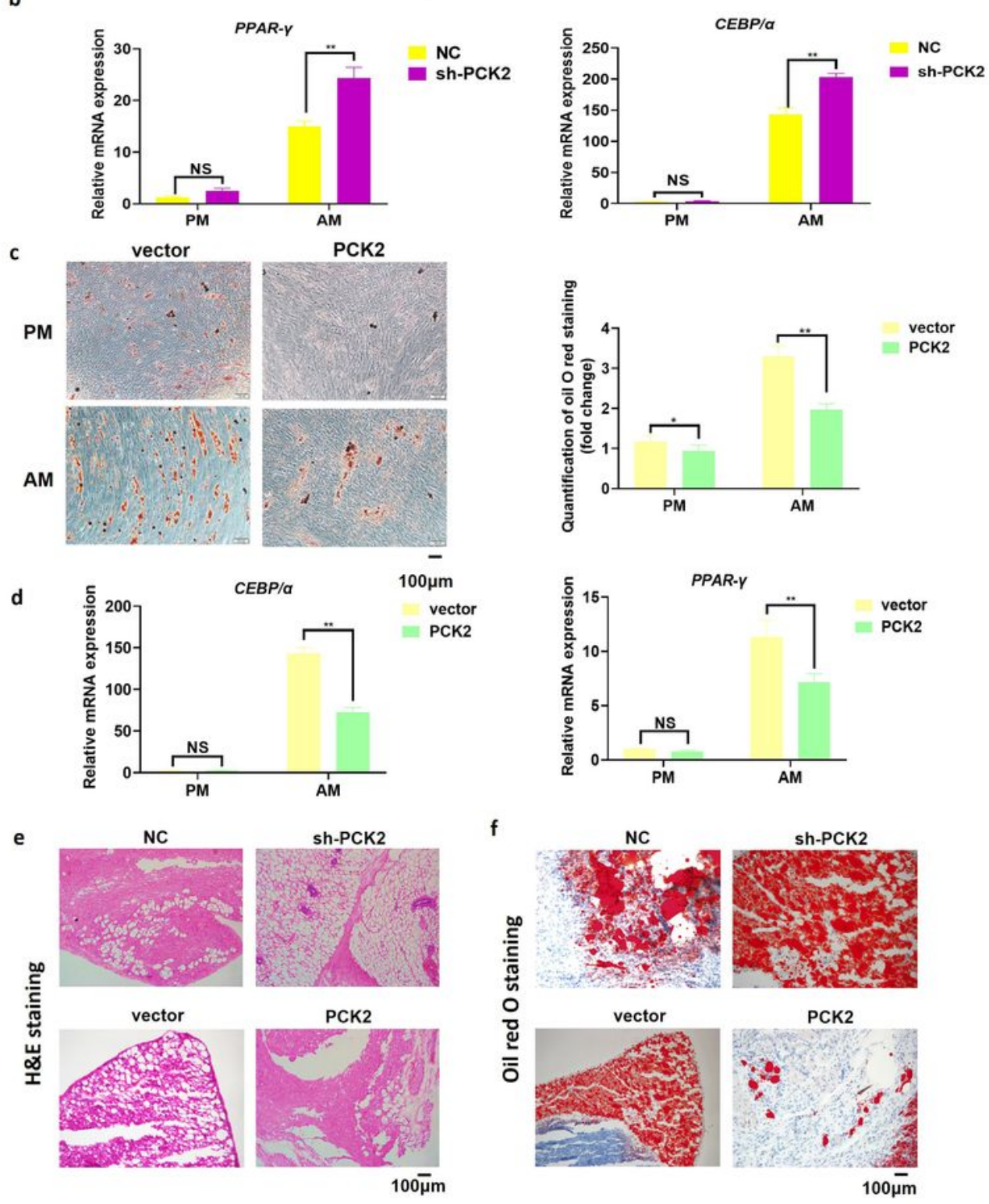

Figure 2 
PCK2 inhibits adipogenic differentiation of hBMMSCs in vitro and in vivo. a Knockdown of PCK2 inhibited adipogenesis as shown by Oil Red $\mathrm{O}$ staining and quantification. b Downregulation of PCK2 promoted the mRNA expression of PPAR-y and C/EBP- $a$, as detected by RT-qPCR. c Overexpression of PCK2 inhibited adipogenesis as shown by Oil Red $\mathrm{O}$ staining and quantification. $\mathrm{d}$ Overexpression of PCK2 inhibited the mRNA expression of PPAR- $\gamma$ and C/EBP-a, as detected by RT-qPCR. e H\&E staining illustrated that PCK2-overexpression cells had fewer adipose tissue-like constructs and PCK2-deficient cells showed more adipose tissue-like constructs in vivo. $\mathrm{f}$ Oil Red $\mathrm{O}$ staining illustrated that PCK2 overexpression group had less adipose tissue-like constructs and PCK2 knockdown group showed more adipose tissuelike constructs in vivo. Data are shown as mean $\pm S D ; n=3$ independent experiments, ${ }^{*}<<0.05, \star \star P<0.01$ 
fig. 2 a
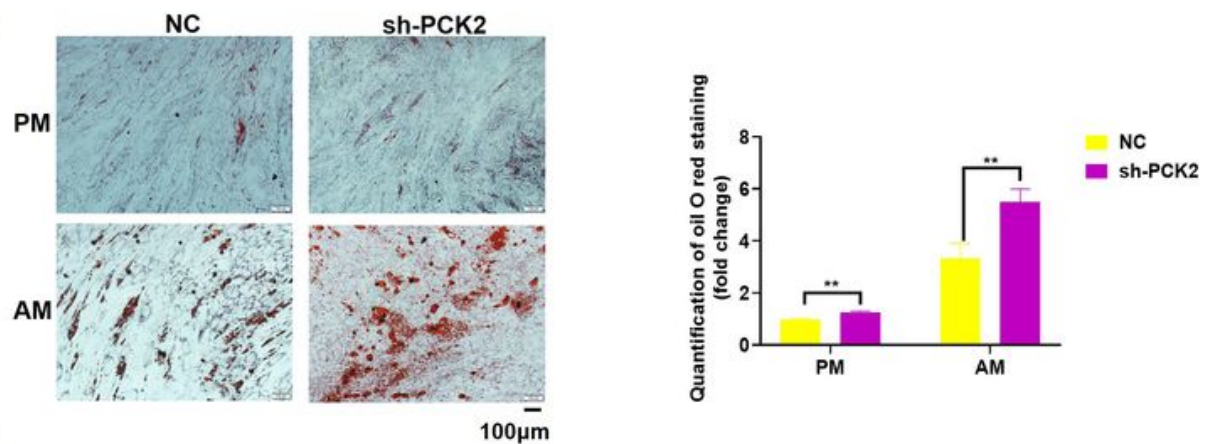

b
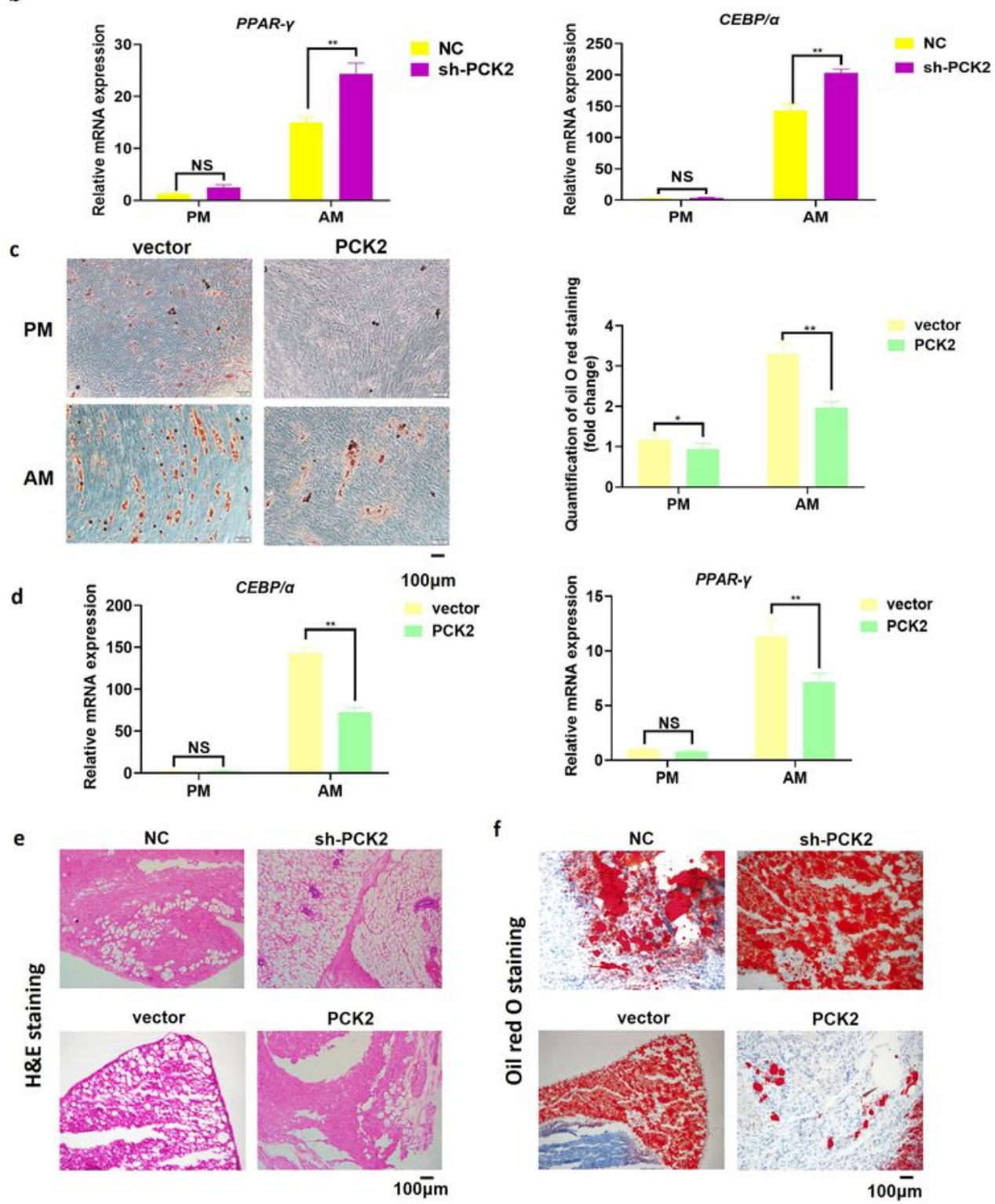

\section{Figure 2}

PCK2 inhibits adipogenic differentiation of hBMMSCs in vitro and in vivo. a Knockdown of PCK2 inhibited adipogenesis as shown by Oil Red $\mathrm{O}$ staining and quantification. b Downregulation of PCK2 promoted the mRNA expression of PPAR-y and C/EBP-a, as detected by RT-qPCR. c Overexpression of PCK2 inhibited adipogenesis as shown by Oil Red $\mathrm{O}$ staining and quantification. $\mathrm{d}$ Overexpression of PCK2 inhibited the mRNA expression of PPAR-y and C/EBP-a, as detected by RT-qPCR. e H\&E staining illustrated 
that PCK2-overexpression cells had fewer adipose tissue-like constructs and PCK2-deficient cells showed more adipose tissue-like constructs in vivo. $\mathrm{f}$ Oil Red $\mathrm{O}$ staining illustrated that PCK2 overexpression group had less adipose tissue-like constructs and PCK2 knockdown group showed more adipose tissuelike constructs in vivo. Data are shown as mean \pm SD; $n=3$ independent experiments, ${ }^{*} P<0.05, * * P<0.01$ fig. 2
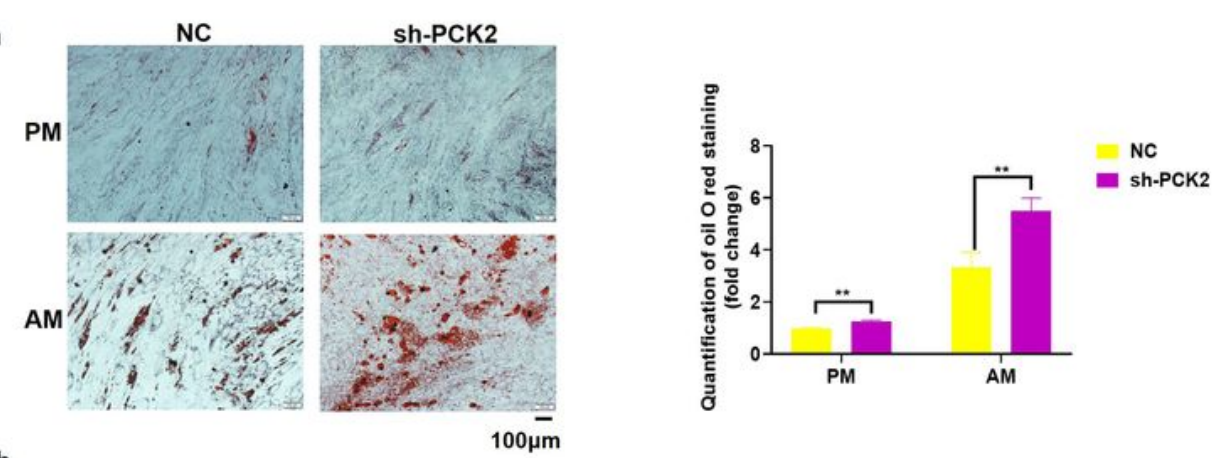

b
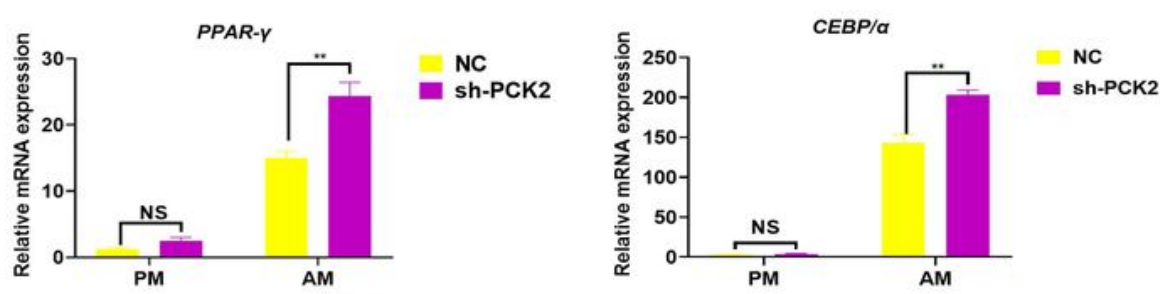

c
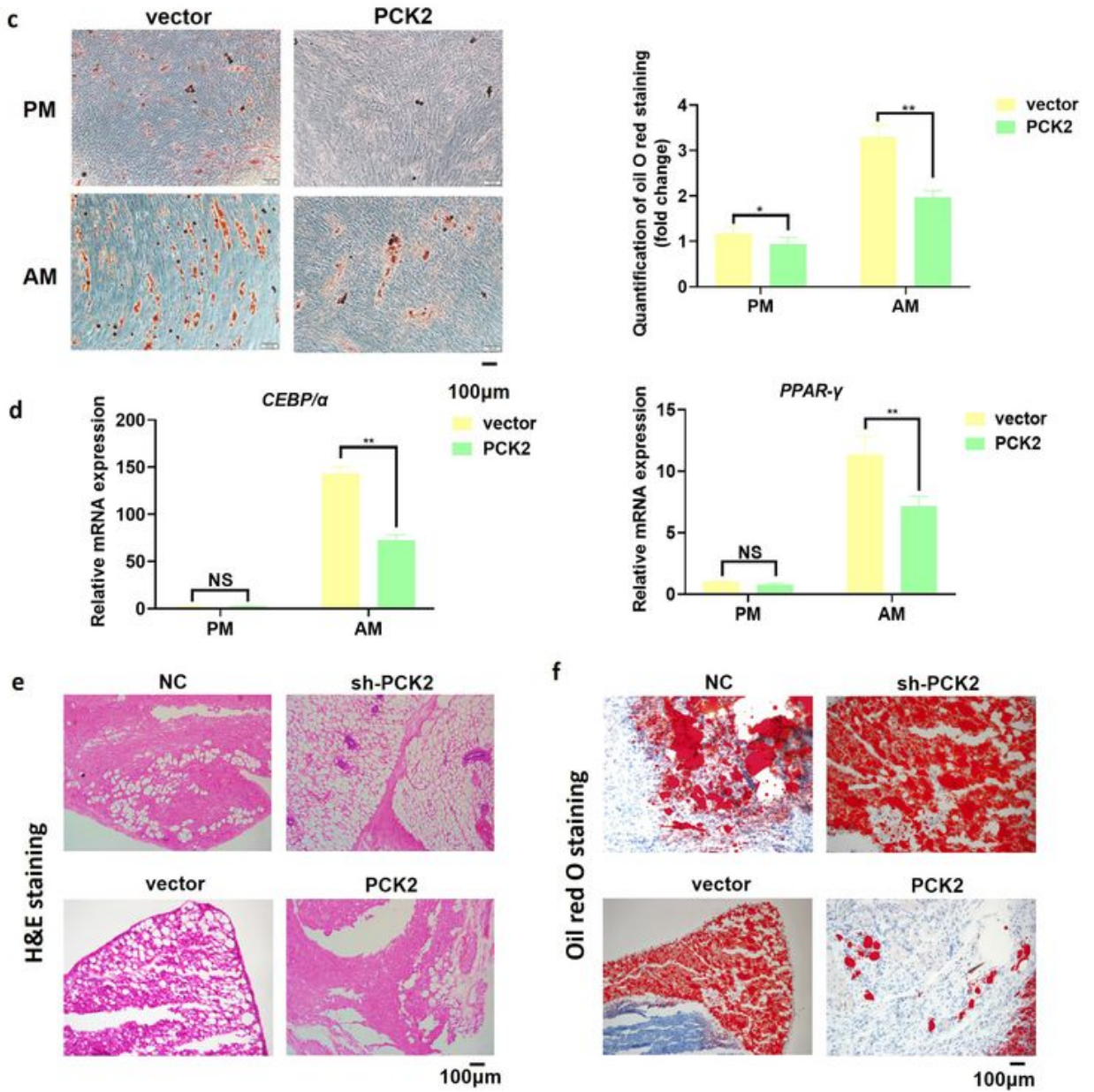

Figure 2 
PCK2 inhibits adipogenic differentiation of hBMMSCs in vitro and in vivo. a Knockdown of PCK2 inhibited adipogenesis as shown by Oil Red $\mathrm{O}$ staining and quantification. b Downregulation of PCK2 promoted the mRNA expression of PPAR-y and C/EBP- $a$, as detected by RT-qPCR. c Overexpression of PCK2 inhibited adipogenesis as shown by Oil Red $\mathrm{O}$ staining and quantification. $\mathrm{d}$ Overexpression of PCK2 inhibited the mRNA expression of PPAR- $\gamma$ and C/EBP-a, as detected by RT-qPCR. e H\&E staining illustrated that PCK2-overexpression cells had fewer adipose tissue-like constructs and PCK2-deficient cells showed more adipose tissue-like constructs in vivo. $\mathrm{f}$ Oil Red $\mathrm{O}$ staining illustrated that PCK2 overexpression group had less adipose tissue-like constructs and PCK2 knockdown group showed more adipose tissuelike constructs in vivo. Data are shown as mean $\pm S D ; n=3$ independent experiments, ${ }^{*}<<0.05, \star \star P<0.01$ 
fig. 3

a
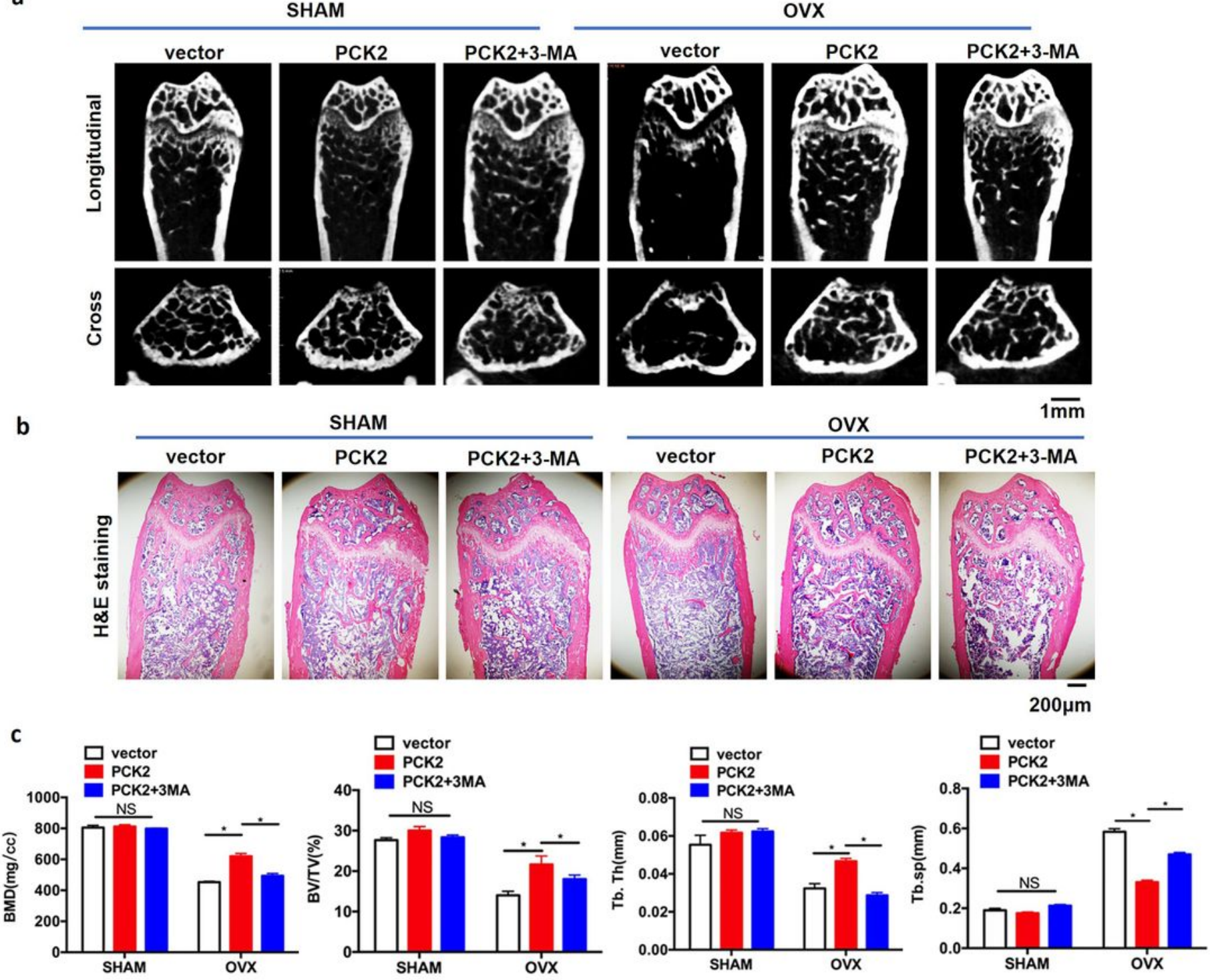

D
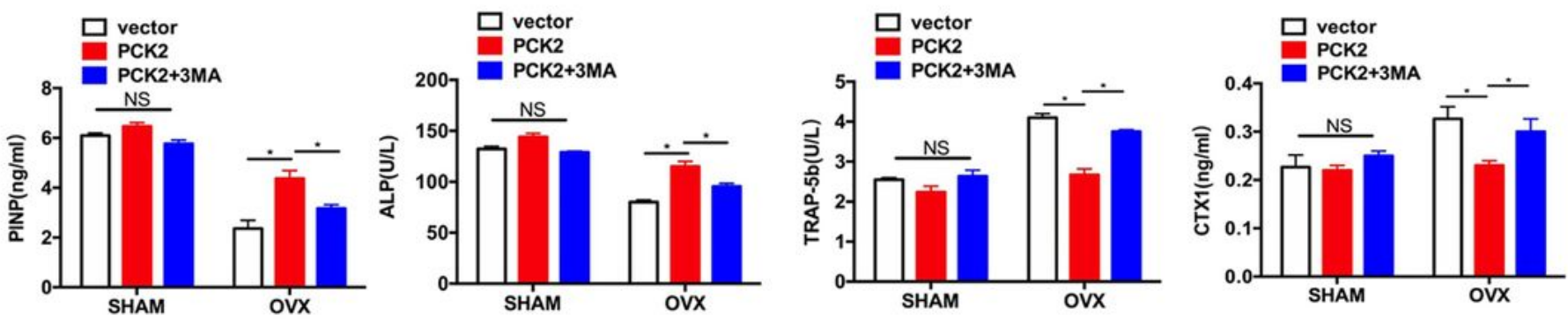

Figure 3

PCK2 suppresses osteoporotic phenotype in OVX mice. a, b Micro-CT and H\&E staining images of femurs in SHAM mice with vector, SHAM mice with PCK2, SHAM mice with PCK2 + 3-MA, OVX mice with vector, OVX mice with PCK2, OVX mice with PCK2 + 3-MA. Scale bar for micro-CT image: 1mm; scale bar for H\&E staining: $200 \mu \mathrm{m}$. c The percentage of bone volume/total volume (BV/TV\%), trabecular thickness (Tb.Th), trabecular separation (Tb.Sp) and bone mineral density (BMD) in the trabecular region of the SHAM mice 
with vector, SHAM mice with PCK2, SHAM mice with PCK2 + 3-MA, OVX mice with vector, OVX mice with PCK2, OVX mice with PCK2 + 3-MA. d Serum levels of P1NP and ALP, which are markers of bone formation, and TRAP-5b and CTX1, which are markers of bone resorption. Data showed the mean \pm SD of experiments, and all the data were carried out in triplicate. ${ }^{*} \mathrm{P}<0.05$, NS: not significant.

fig. 3

a SHAM

ovx
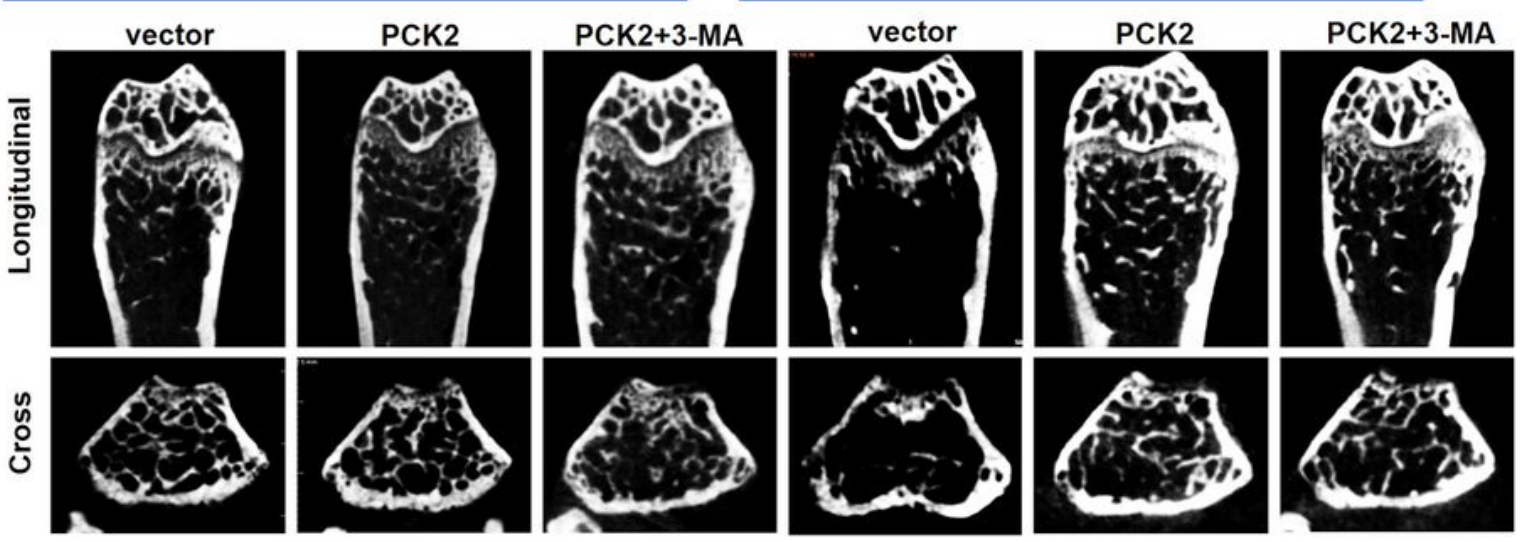

b
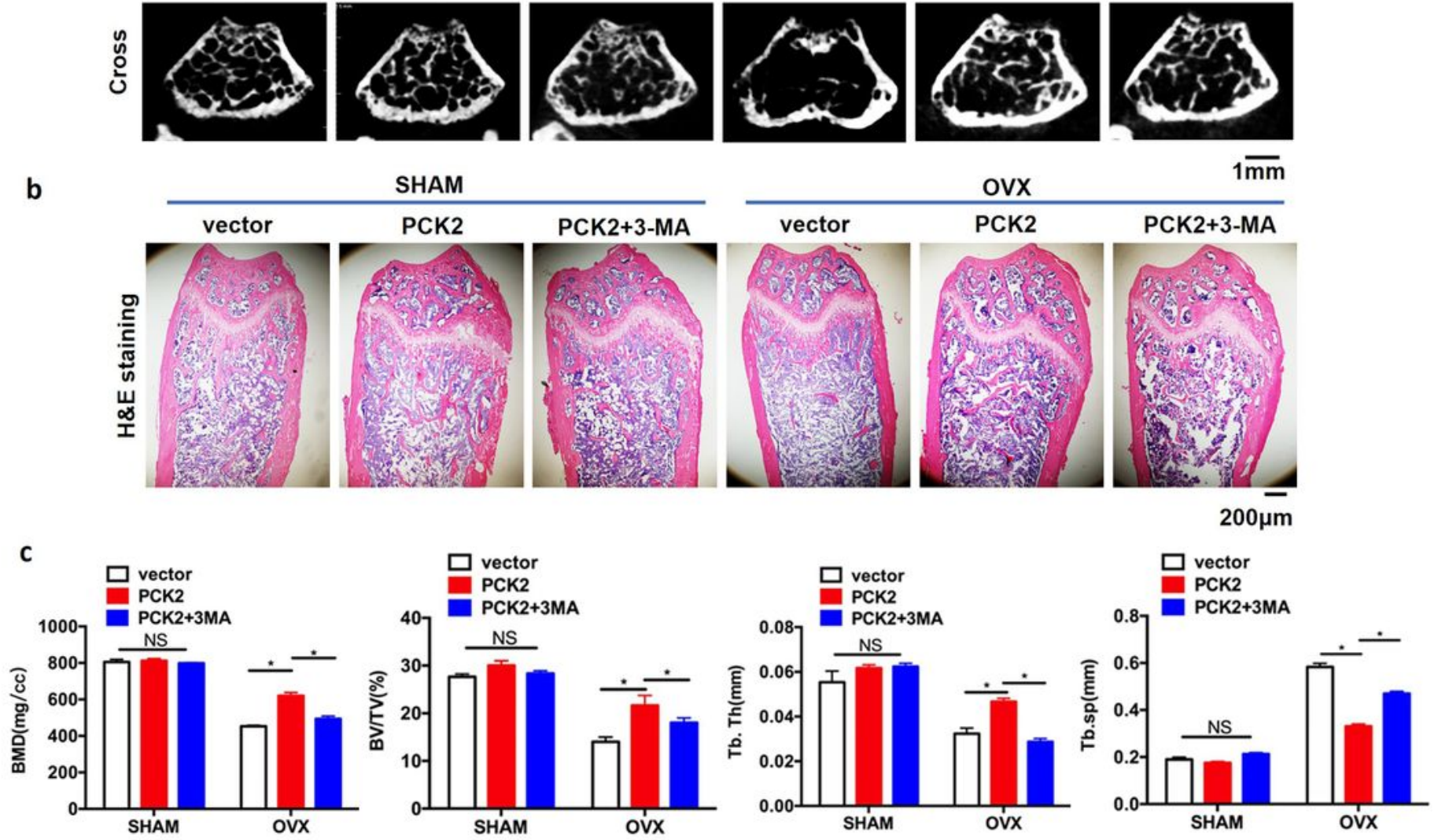

D
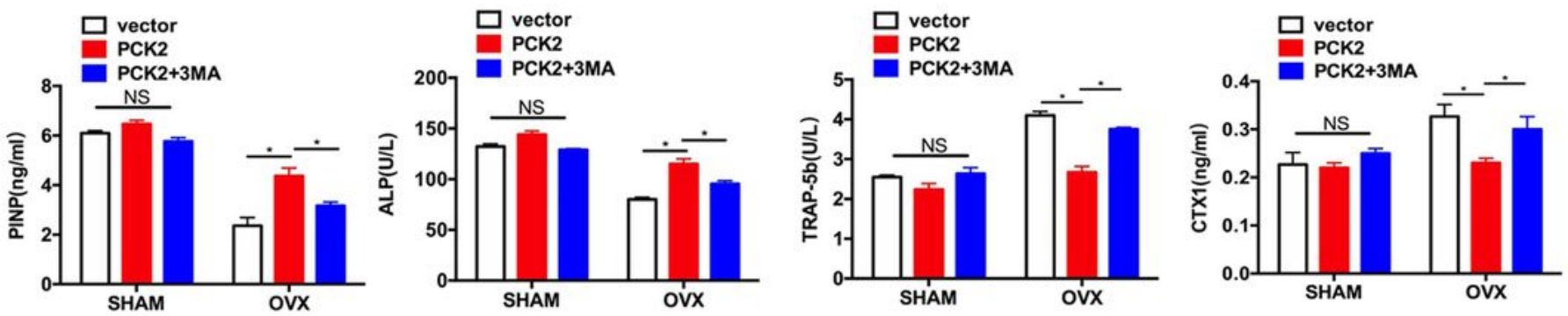

Figure 3 
PCK2 suppresses osteoporotic phenotype in OVX mice. a, b Micro-CT and H\&E staining images of femurs in SHAM mice with vector, SHAM mice with PCK2, SHAM mice with PCK2 + 3-MA, OVX mice with vector, OVX mice with PCK2, OVX mice with PCK2 + 3-MA. Scale bar for micro-CT image: $1 \mathrm{~mm}$; scale bar for H\&E staining: $200 \mu \mathrm{m}$. c The percentage of bone volume/total volume (BV/TV\%), trabecular thickness (Tb.Th), trabecular separation (Tb.Sp) and bone mineral density (BMD) in the trabecular region of the SHAM mice with vector, SHAM mice with PCK2, SHAM mice with PCK2 + 3-MA, OVX mice with vector, OVX mice with PCK2, OVX mice with PCK2 + 3-MA. d Serum levels of P1NP and ALP, which are markers of bone

formation, and TRAP-5b and CTX1, which are markers of bone resorption. Data showed the mean \pm SD of experiments, and all the data were carried out in triplicate. ${ }^{*} \mathrm{P}<0.05$, NS: not significant. 
fig. 3

a
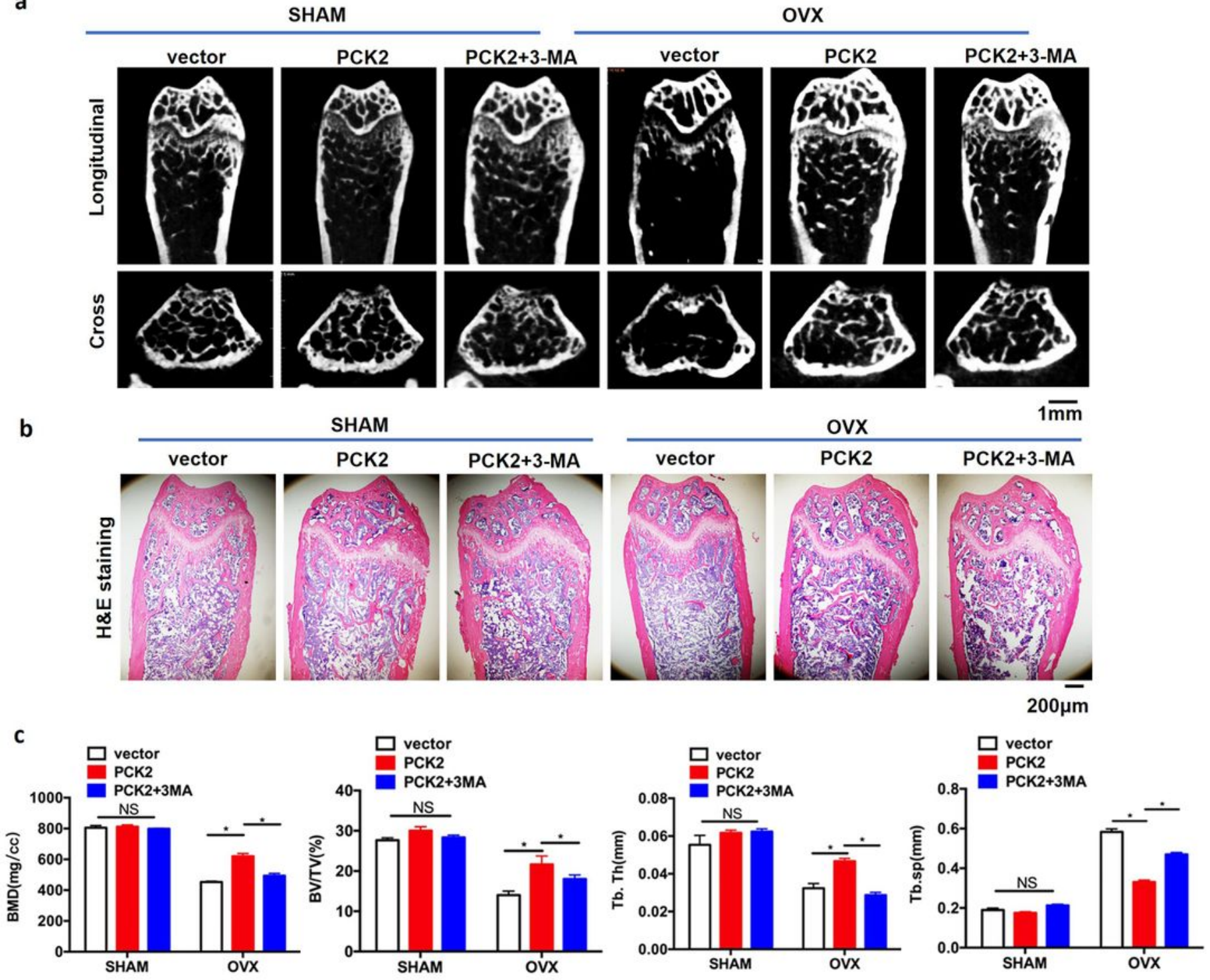

D
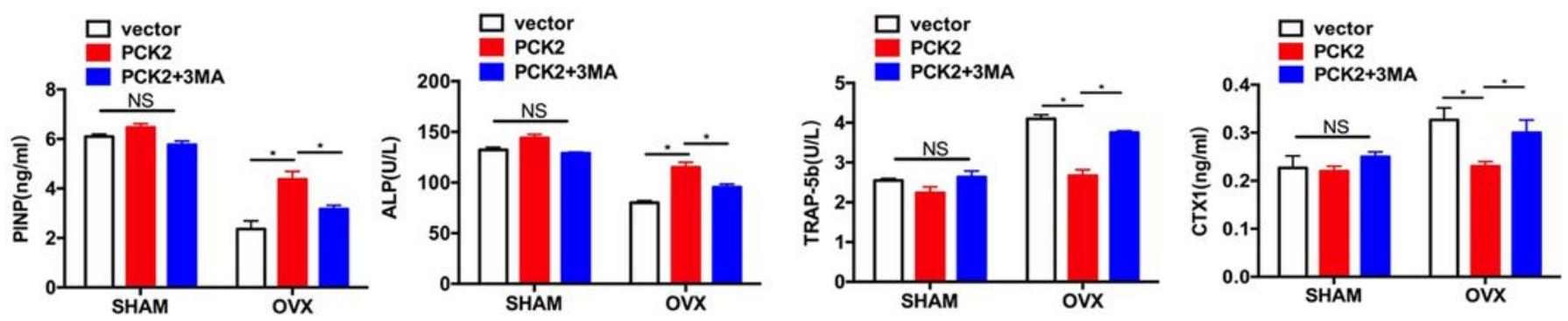

Figure 3

PCK2 suppresses osteoporotic phenotype in OVX mice. a, b Micro-CT and H\&E staining images of femurs in SHAM mice with vector, SHAM mice with PCK2, SHAM mice with PCK2 + 3-MA, OVX mice with vector, OVX mice with PCK2, OVX mice with PCK2 + 3-MA. Scale bar for micro-CT image: 1mm; scale bar for H\&E staining: $200 \mu \mathrm{m}$. c The percentage of bone volume/total volume (BV/TV\%), trabecular thickness (Tb.Th), trabecular separation (Tb.Sp) and bone mineral density (BMD) in the trabecular region of the SHAM mice 
with vector, SHAM mice with PCK2, SHAM mice with PCK2 + 3-MA, OVX mice with vector, OVX mice with PCK2, OVX mice with PCK2 + 3-MA. d Serum levels of P1NP and ALP, which are markers of bone formation, and TRAP-5b and CTX1, which are markers of bone resorption. Data showed the mean \pm SD of experiments, and all the data were carried out in triplicate. ${ }^{*} \mathrm{P}<0.05$, NS: not significant.

\section{fig. 4}

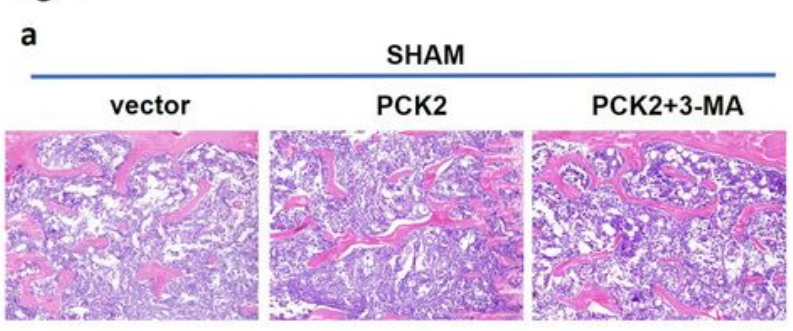

$100 \overline{\mu m}$

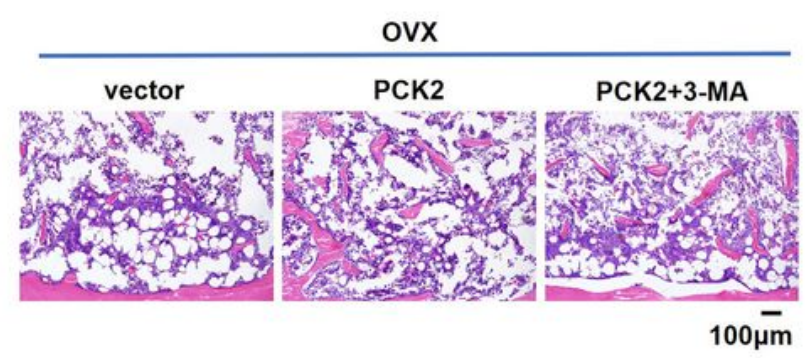

b

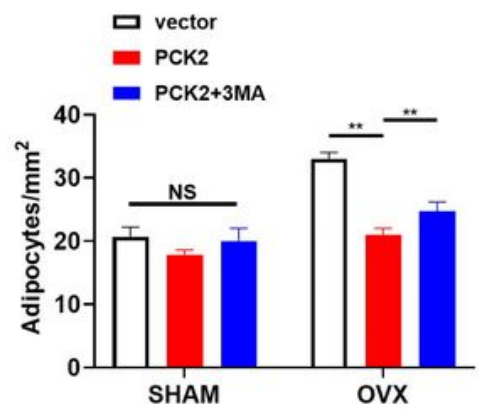

C

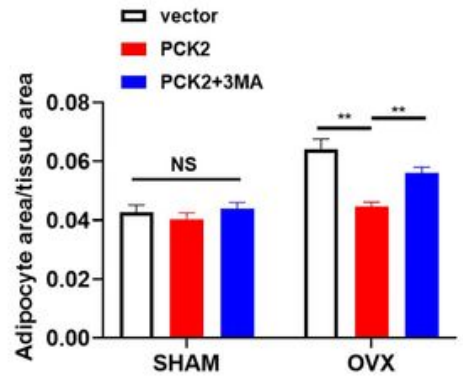

Figure 4 PCK2 inhibits adipose foramation in OVX mice

Figure 4 
PCK2 inhibits adipose foramation in OVX mice. a H\&E staining of femurs from SHAM mice with vector, SHAM mice with PCK2, SHAM mice with PCK2 + 3-MA, OVX mice with vector, OVX mice with PCK2, OVX mice with PCK2 + 3-MA. b Adipocyte count and adipocyte area/tissue based on H\&E staining of femurs in SHAM mice with vector, SHAM mice with PCK2, SHAM mice with PCK2 + 3-MA, OVX mice with vector, OVX mice with PCK2, OVX mice with PCK2 + 3-MA. Data are shown by the mean \pm SD, and all the experiments were carried out in triplicate. ${ }^{*} \mathrm{P}<0.01$, NS: not significant.

fig. 4

a

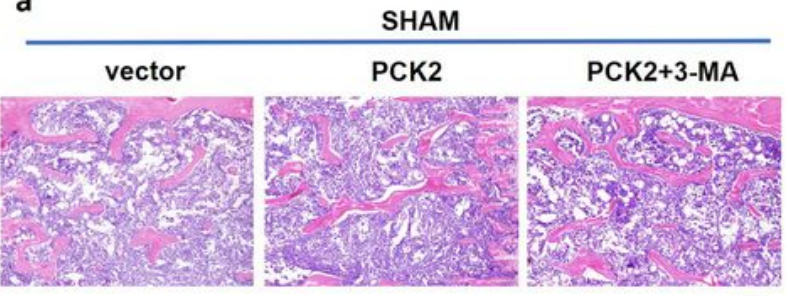

$100 \bar{m}$

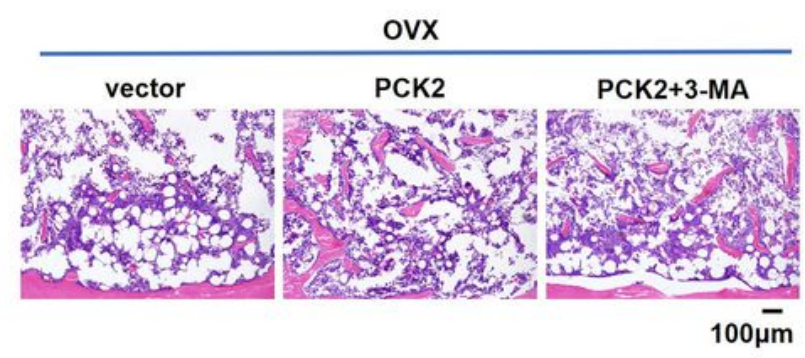

b

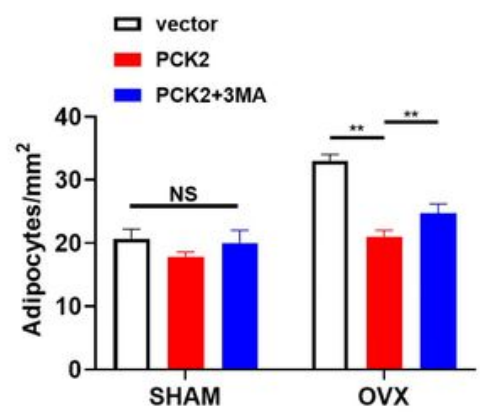

C

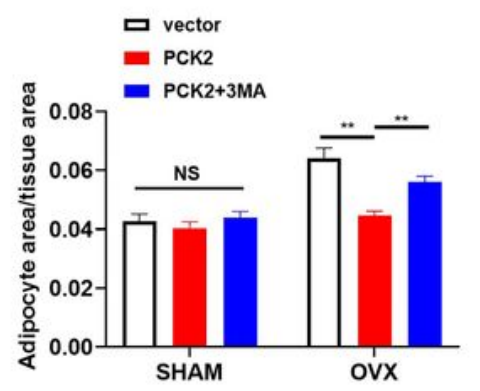


PCK2 inhibits adipose foramation in OVX mice. a H\&E staining of femurs from SHAM mice with vector, SHAM mice with PCK2, SHAM mice with PCK2 + 3-MA, OVX mice with vector, OVX mice with PCK2, OVX mice with PCK2 + 3-MA. b Adipocyte count and adipocyte area/tissue based on H\&E staining of femurs in SHAM mice with vector, SHAM mice with PCK2, SHAM mice with PCK2 + 3-MA, OVX mice with vector, OVX mice with PCK2, OVX mice with PCK2 + 3-MA. Data are shown by the mean \pm SD, and all the experiments were carried out in triplicate. ${ }^{*} \mathrm{P}<0.01$, NS: not significant.

fig. 4

a

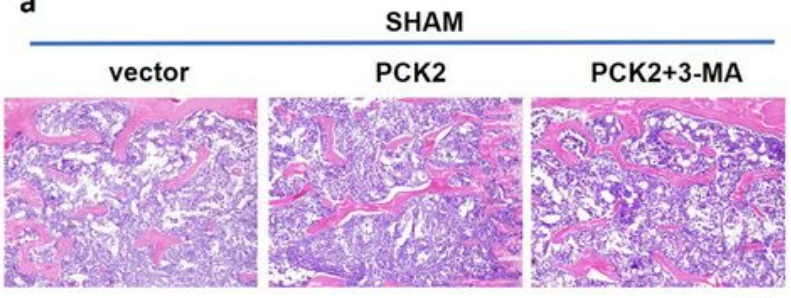

$100 \overline{\mathrm{mm}}$

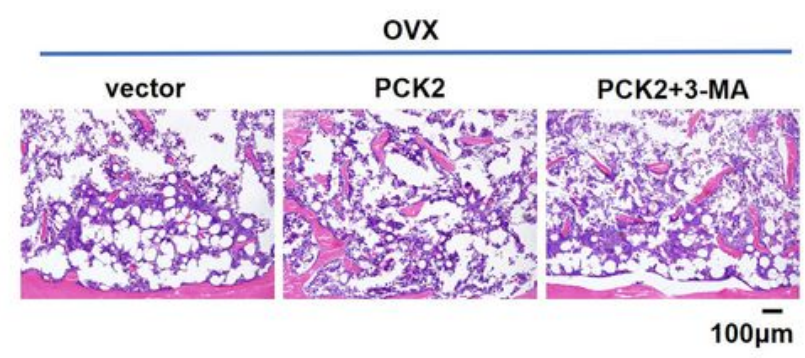

b

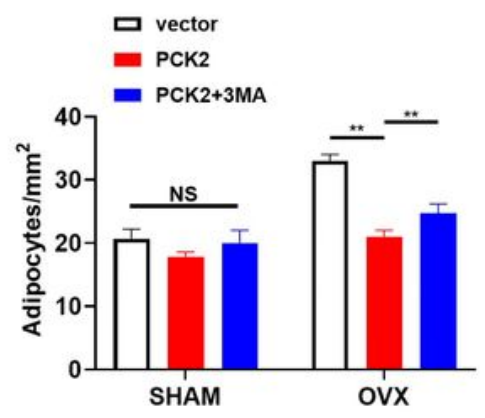

C

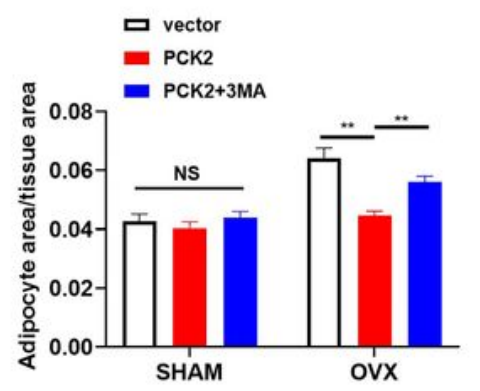


PCK2 inhibits adipose foramation in OVX mice. a H\&E staining of femurs from SHAM mice with vector, SHAM mice with PCK2, SHAM mice with PCK2 + 3-MA, OVX mice with vector, OVX mice with PCK2, OVX mice with PCK2 + 3-MA. b Adipocyte count and adipocyte area/tissue based on H\&E staining of femurs in SHAM mice with vector, SHAM mice with PCK2, SHAM mice with PCK2 + 3-MA, OVX mice with vector, OVX mice with PCK2, OVX mice with PCK2 + 3-MA. Data are shown by the mean \pm SD, and all the experiments were carried out in triplicate. ${ }^{*} \mathrm{P}<0.01$, NS: not significant.

fig.5

a

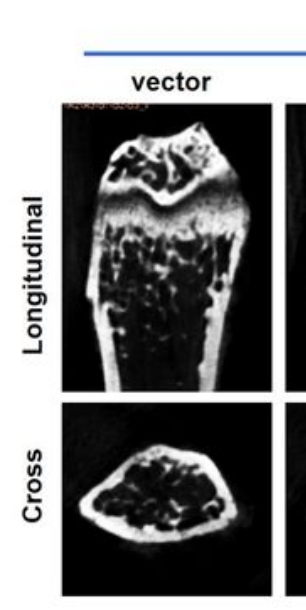

$6 w$
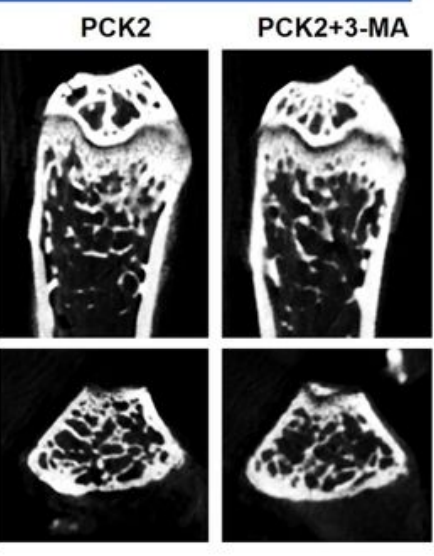

b

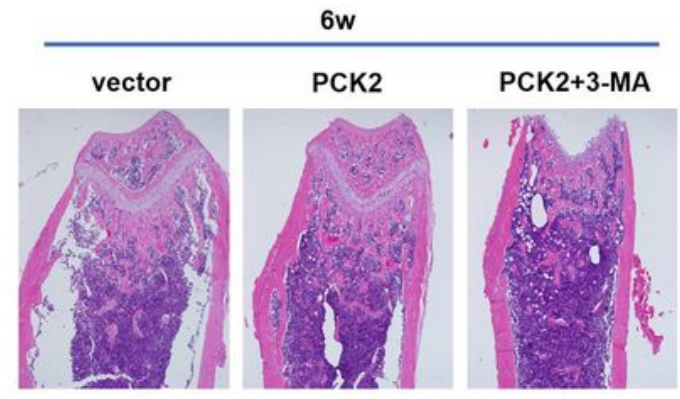

C
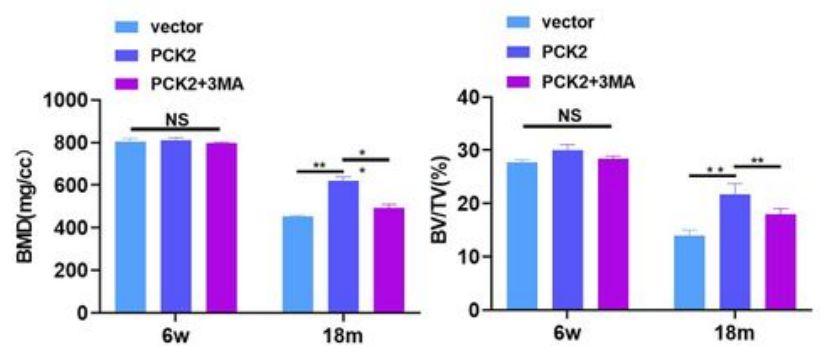

d
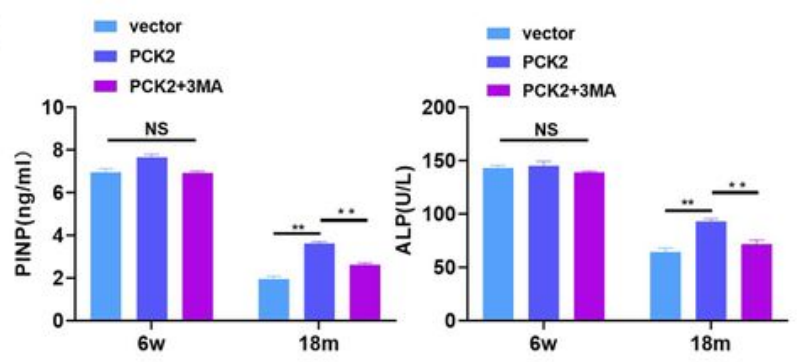
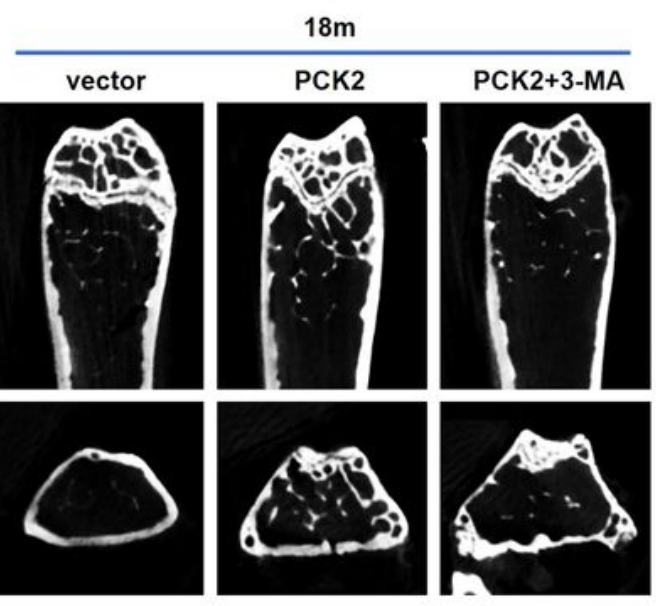

$\overline{1 \mathrm{~mm}}$
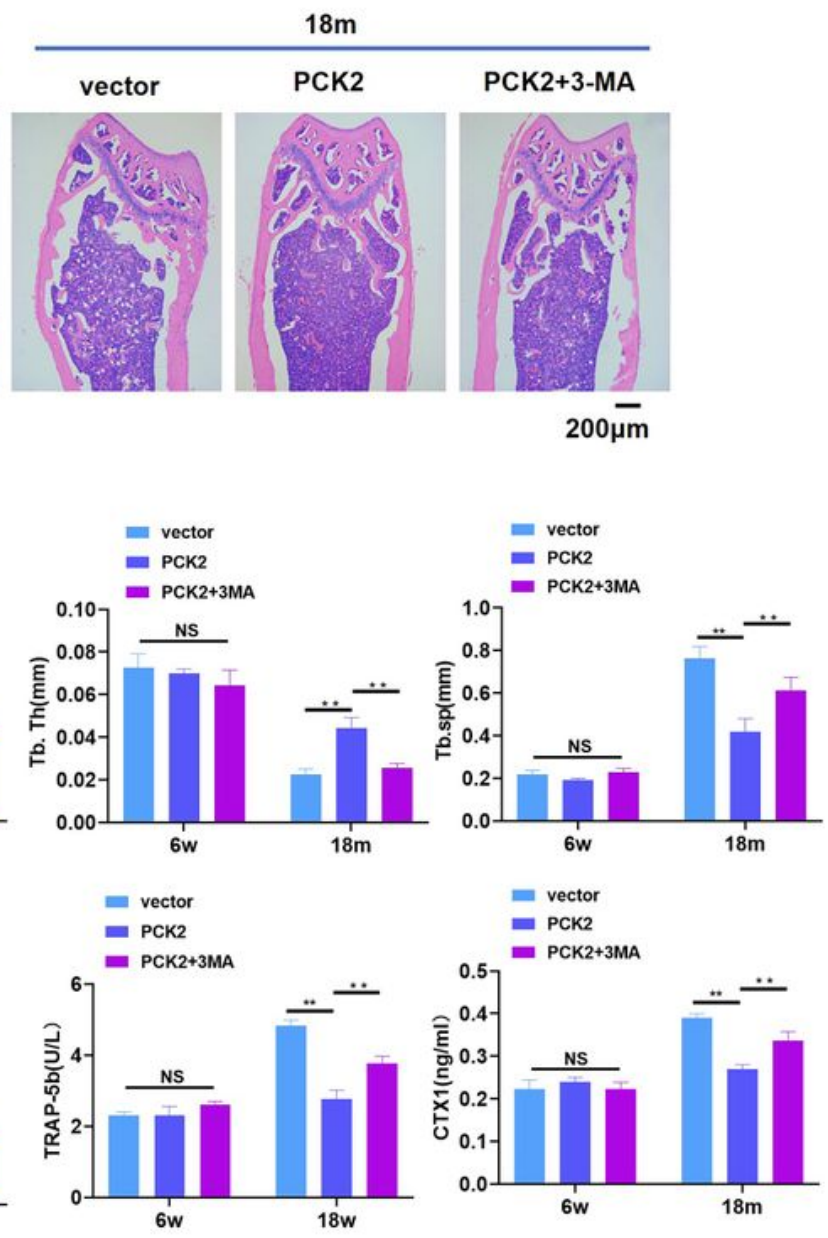

Figure 5 
PCK2 reverses bone loss in aged mice. $a, b$ Micro-CT and H\&E staining images of femurs in $6 \mathrm{w}$ mice with vector, $6 \mathrm{w}$ mice with PCK2, $6 \mathrm{w}$ mice with PCK2 + 3-MA, 18m mice with vector, $18 \mathrm{~m}$ mice with PCK2, 18m mice with PCK2 + 3-MA. Scale bar for micro-CT image: $1 \mathrm{~mm}$; scale bar for H\&E staining: $200 \mu \mathrm{m}$. c The percentage of bone volume/total volume (BV/TV\%), trabecular thickness (Tb.Th), trabecular separation (Tb.Sp) and bone mineral density (BMD) in the trabecular region of the $6 \mathrm{w}$ mice with vector, $6 \mathrm{w}$ mice with PCK2, 6w mice with PCK2 + 3-MA, 18m mice with vector, $18 \mathrm{~m}$ mice with PCK2, 18m mice with PCK2 + 3MA. d Serum levels of P1NP and ALP, which are markers of bone formation, and TRAP-5b and CTX1, which are markers of bone resorption in $6 \mathrm{w}$ mice with vector, $6 \mathrm{w}$ mice with PCK2, $6 \mathrm{w}$ mice with PCK2 + 3MA, $18 \mathrm{~m}$ mice with vector, $18 \mathrm{~m}$ mice with PCK2, $18 \mathrm{~m}$ mice with PCK2 + 3-MA. Data are shown by the mean $\pm S D$, and all the experiments were carried out in triplicate. ${ }^{*} P<0.05$, NS: not significant. 
fig.5

a

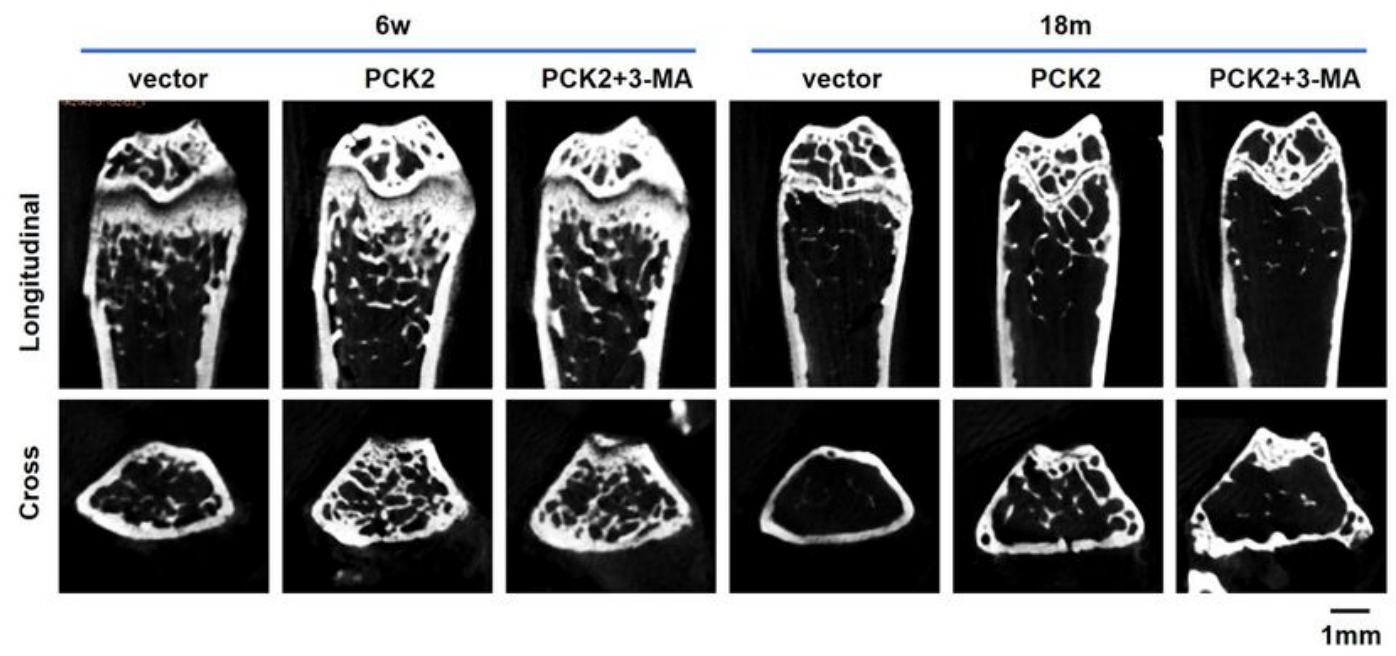

b
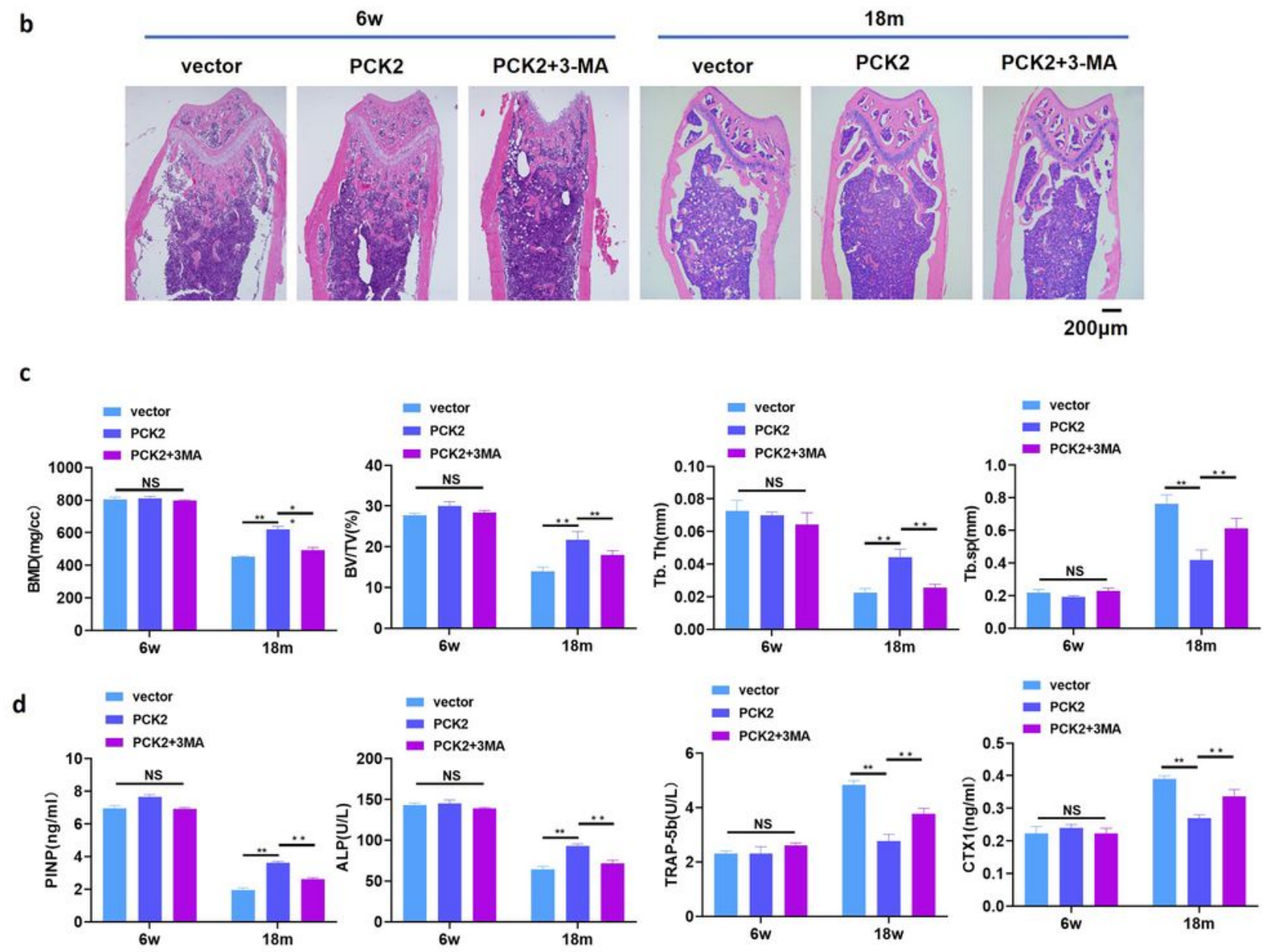

Figure 5

PCK2 reverses bone loss in aged mice. a, b Micro-CT and H\&E staining images of femurs in 6w mice with vector, 6 w mice with PCK2, 6w mice with PCK2 + 3-MA, 18m mice with vector, 18m mice with PCK2, 18m mice with PCK2 + 3-MA. Scale bar for micro-CT image: 1mm; scale bar for H\&E staining: 200 $\mu \mathrm{m}$. c The percentage of bone volume/total volume (BV/TV\%), trabecular thickness (Tb.Th), trabecular separation (Tb.Sp) and bone mineral density (BMD) in the trabecular region of the 6 w mice with vector, 6 w mice with 
PCK2, 6w mice with PCK2 + 3-MA, 18m mice with vector, 18m mice with PCK2, 18m mice with PCK2 + 3MA. d Serum levels of P1NP and ALP, which are markers of bone formation, and TRAP-5b and CTX1, which are markers of bone resorption in $6 \mathrm{w}$ mice with vector, $6 \mathrm{w}$ mice with PCK2, 6w mice with PCK2 + 3MA, $18 \mathrm{~m}$ mice with vector, $18 \mathrm{~m}$ mice with PCK2, $18 \mathrm{~m}$ mice with PCK2 + 3-MA. Data are shown by the mean $\pm S D$, and all the experiments were carried out in triplicate. ${ }^{*} P<0.05$, NS: not significant.

fig.5

a
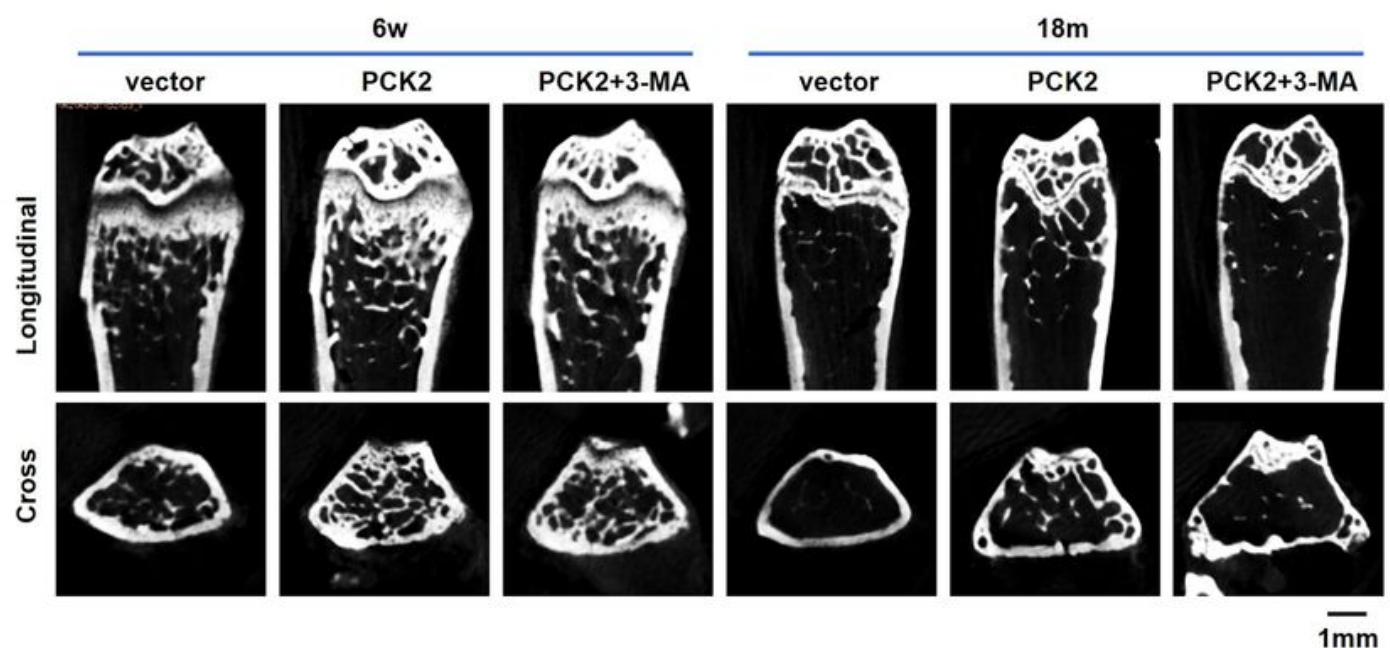

b
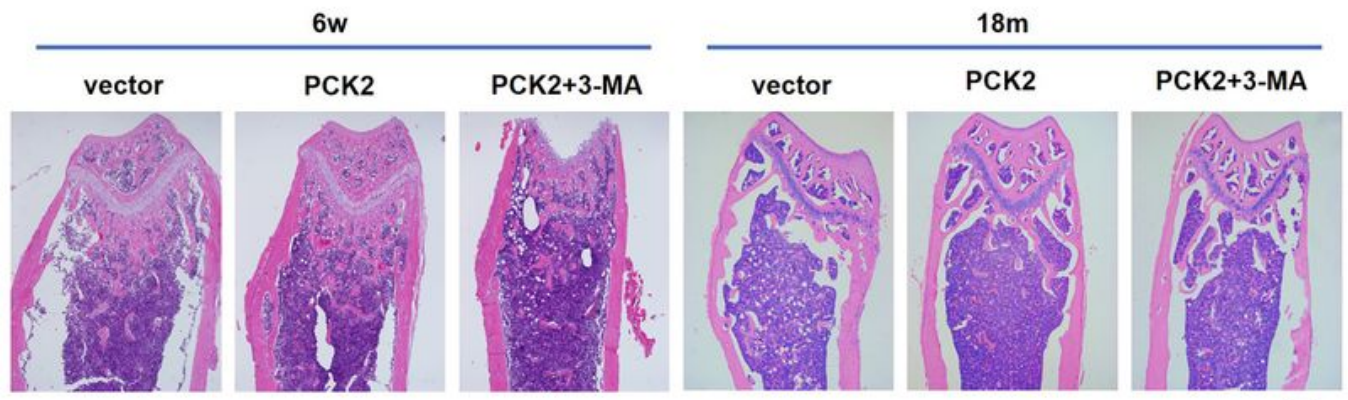

$200 \overline{\mu m}$

C
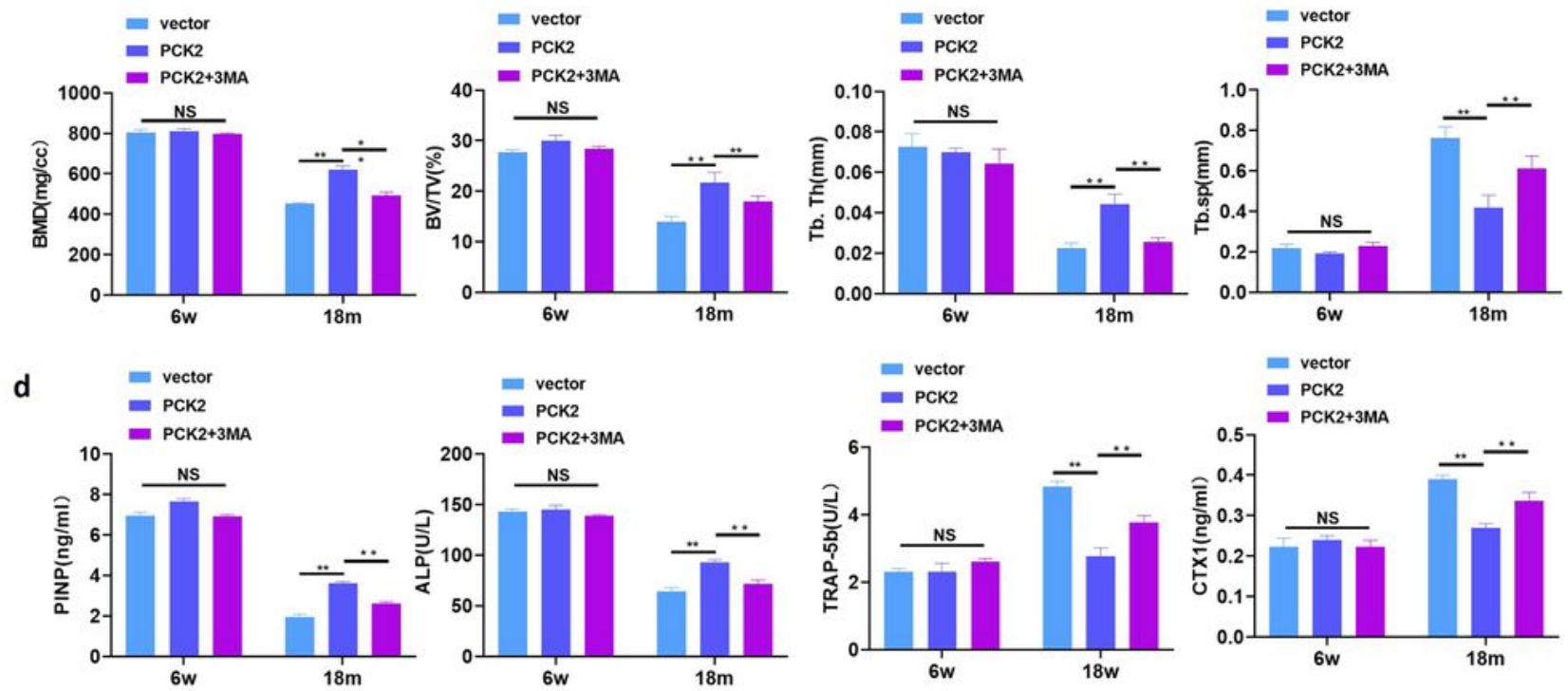

Figure 5 
PCK2 reverses bone loss in aged mice. $a, b$ Micro-CT and H\&E staining images of femurs in $6 \mathrm{w}$ mice with vector, $6 \mathrm{w}$ mice with PCK2, $6 \mathrm{w}$ mice with PCK2 + 3-MA, 18m mice with vector, $18 \mathrm{~m}$ mice with PCK2, 18m mice with PCK2 + 3-MA. Scale bar for micro-CT image: $1 \mathrm{~mm}$; scale bar for H\&E staining: $200 \mu \mathrm{m}$. c The percentage of bone volume/total volume (BV/TV\%), trabecular thickness (Tb.Th), trabecular separation (Tb.Sp) and bone mineral density (BMD) in the trabecular region of the $6 \mathrm{w}$ mice with vector, $6 \mathrm{w}$ mice with PCK2, 6w mice with PCK2 + 3-MA, 18m mice with vector, $18 \mathrm{~m}$ mice with PCK2, $18 \mathrm{~m}$ mice with PCK2 + 3MA. d Serum levels of P1NP and ALP, which are markers of bone formation, and TRAP-5b and CTX1, which are markers of bone resorption in $6 \mathrm{w}$ mice with vector, $6 \mathrm{w}$ mice with PCK2, $6 \mathrm{w}$ mice with PCK2 + 3MA, $18 \mathrm{~m}$ mice with vector, $18 \mathrm{~m}$ mice with PCK2, $18 \mathrm{~m}$ mice with PCK2 + 3-MA. Data are shown by the mean $\pm S D$, and all the experiments were carried out in triplicate. ${ }^{*} P<0.05$, NS: not significant.

\section{fig. 6}

a

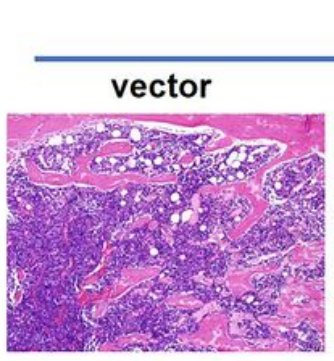

$6 w$
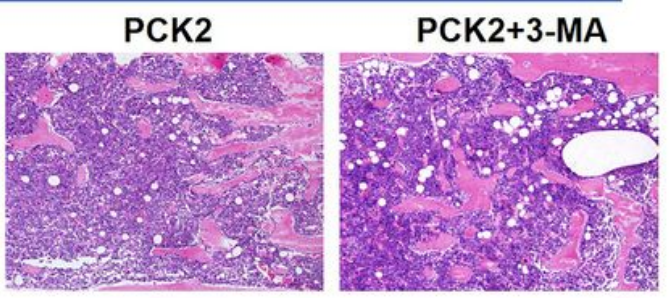

$100 \mu \mathrm{m}$

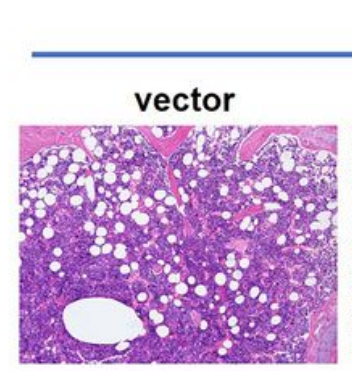

$18 \mathrm{~m}$
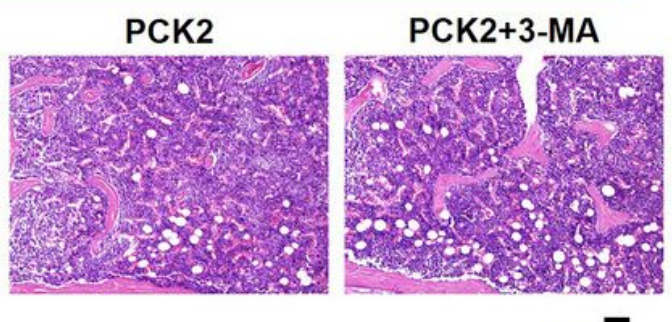

$100 \overline{\mu m}$ b

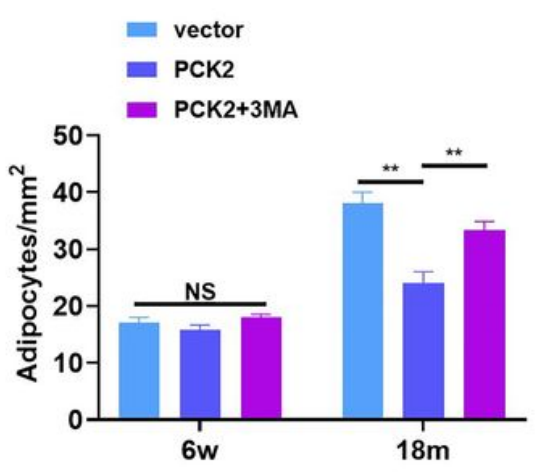

c

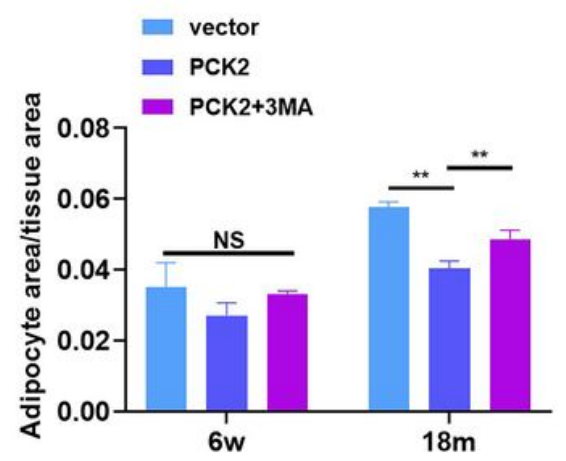

\section{Figure 6}

PCK2 resists adipose accumulation in aged mice. a H\&E staining of femurs from $6 \mathrm{w}$ mice with vector, $6 \mathrm{w}$ mice with PCK2, $6 \mathrm{w}$ mice with PCK2 + 3-MA, $18 \mathrm{~m}$ mice with vector, $18 \mathrm{~m}$ mice with PCK2, $18 \mathrm{~m}$ mice with PCK2 + 3-MA. b Adipocyte count and adipocyte area/tissue based on H\&E staining of femurs in SHAM mice with vector, $6 \mathrm{w}$ mice with vector, $6 \mathrm{w}$ mice with PCK2, 6w mice with PCK2 + 3-MA, 18m mice with vector, $18 \mathrm{~m}$ mice with PCK2, 18m mice with PCK2 + 3-MA. Data are shown by the mean \pm SD, and all the experiments were carried out in triplicate. ${ }^{*} \mathrm{P}<0.01$, NS: not significant. 
fig.6

a

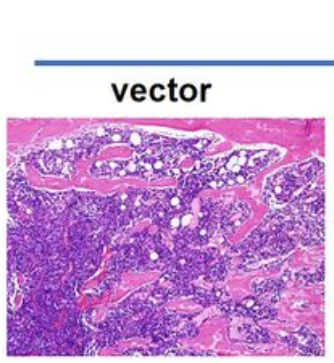

$6 w$

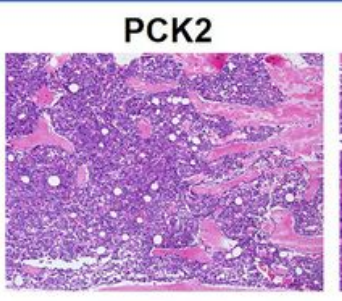

PCK2+3-MA

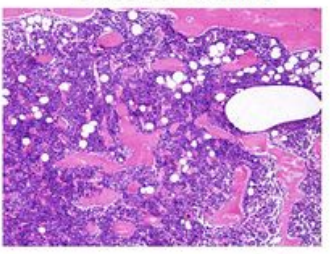

$100 \mu \bar{m}$

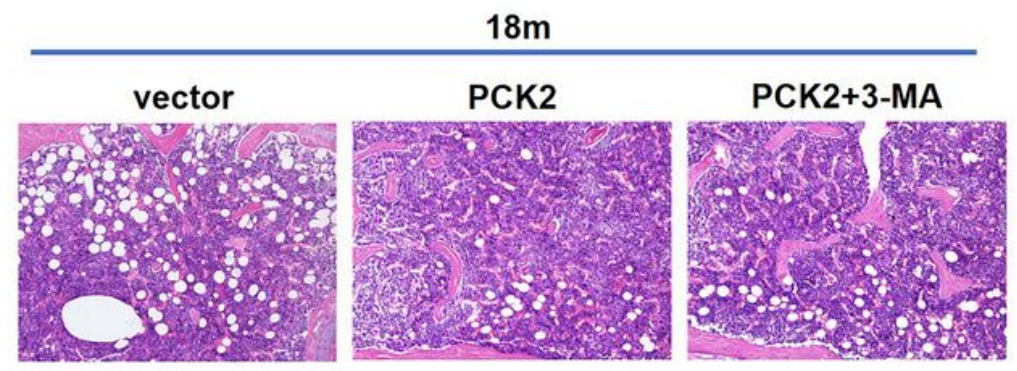

$100 \overline{\mu m}$ b

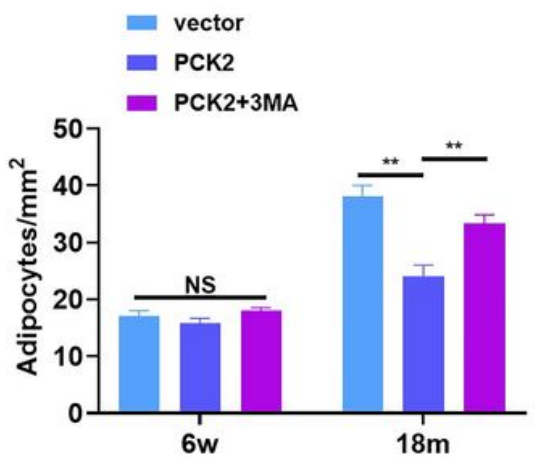

C

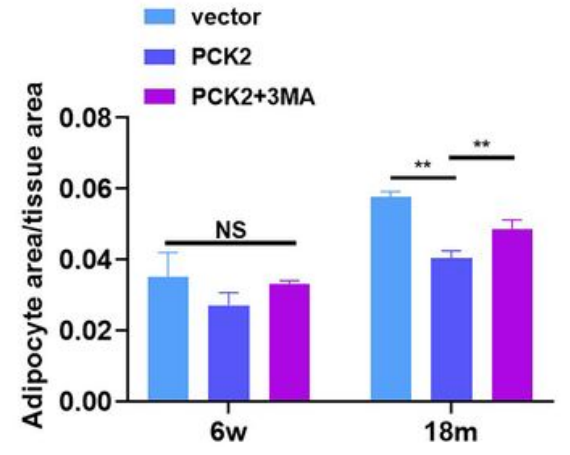

Figure 6

PCK2 resists adipose accumulation in aged mice. a H\&E staining of femurs from $6 \mathrm{w}$ mice with vector, $6 \mathrm{w}$ mice with PCK2, 6w mice with PCK2 + 3-MA, 18m mice with vector, $18 \mathrm{~m}$ mice with PCK2, $18 \mathrm{~m}$ mice with PCK2 + 3-MA. b Adipocyte count and adipocyte area/tissue based on H\&E staining of femurs in SHAM mice with vector, $6 \mathrm{w}$ mice with vector, $6 \mathrm{w}$ mice with PCK2, 6w mice with PCK2 + 3-MA, 18m mice with vector, $18 \mathrm{~m}$ mice with PCK2, $18 \mathrm{~m}$ mice with PCK2 + 3-MA. Data are shown by the mean \pm SD, and all the experiments were carried out in triplicate. ${ }^{*} \mathrm{P}<0.01$, NS: not significant. 
fig.6

a

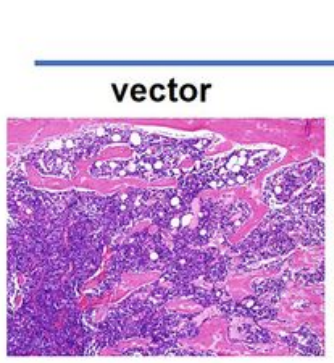

$6 w$

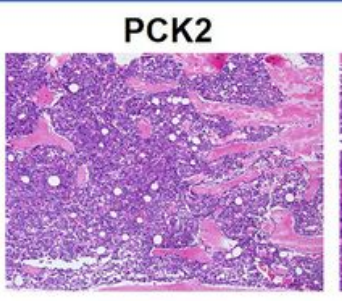

PCK2+3-MA

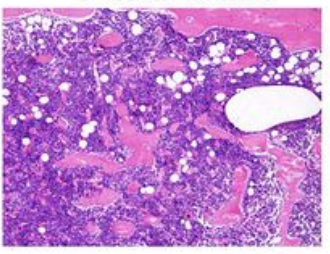

$100 \mu \bar{m}$

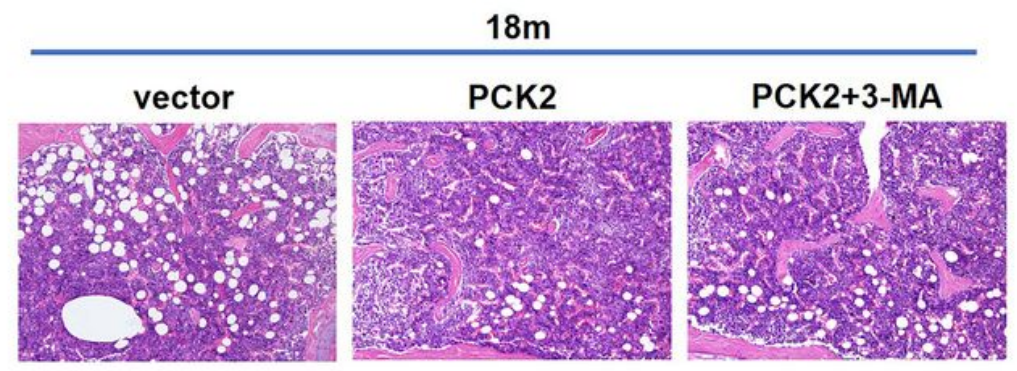

$100 \overline{\mu m}$ b

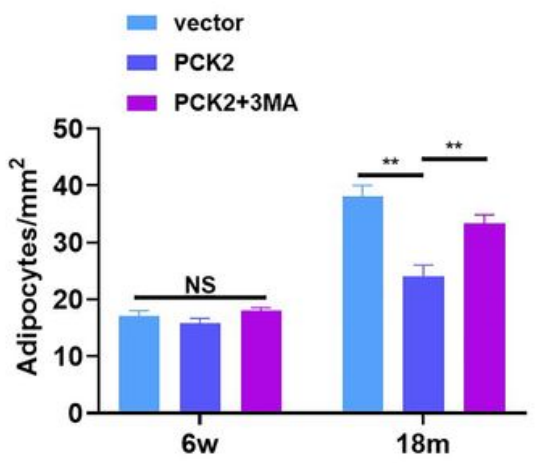

C

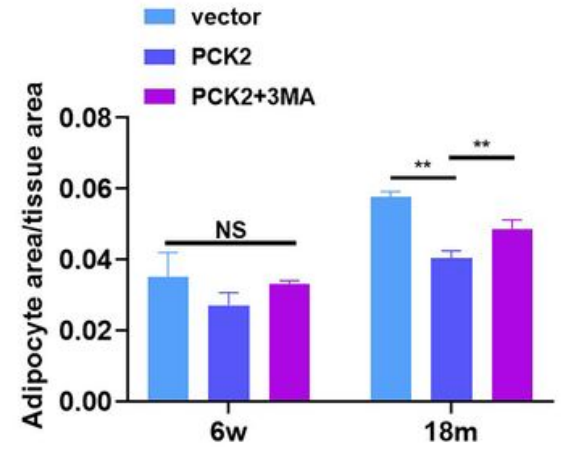

Figure 6

PCK2 resists adipose accumulation in aged mice. a H\&E staining of femurs from $6 \mathrm{w}$ mice with vector, $6 \mathrm{w}$ mice with PCK2, 6w mice with PCK2 + 3-MA, 18m mice with vector, $18 \mathrm{~m}$ mice with PCK2, $18 \mathrm{~m}$ mice with PCK2 + 3-MA. b Adipocyte count and adipocyte area/tissue based on H\&E staining of femurs in SHAM mice with vector, $6 \mathrm{w}$ mice with vector, $6 \mathrm{w}$ mice with PCK2, 6w mice with PCK2 + 3-MA, 18m mice with vector, $18 \mathrm{~m}$ mice with PCK2, $18 \mathrm{~m}$ mice with PCK2 + 3-MA. Data are shown by the mean \pm SD, and all the experiments were carried out in triplicate. ${ }^{*} \mathrm{P}<0.01$, NS: not significant. 
fig.7

a

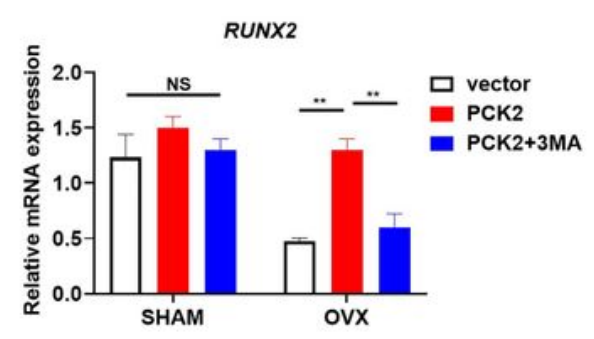

C

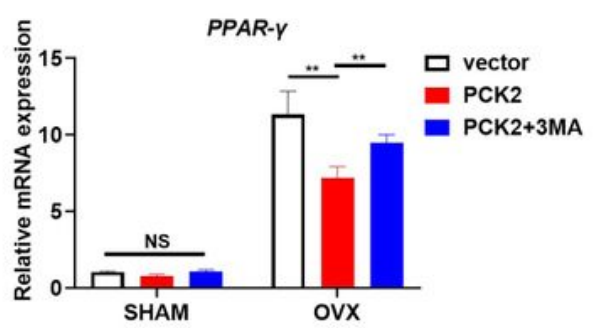

e

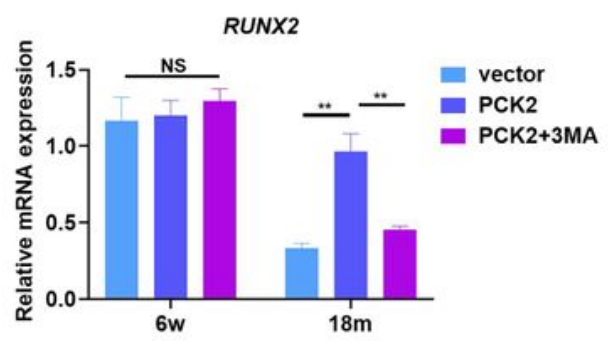

g

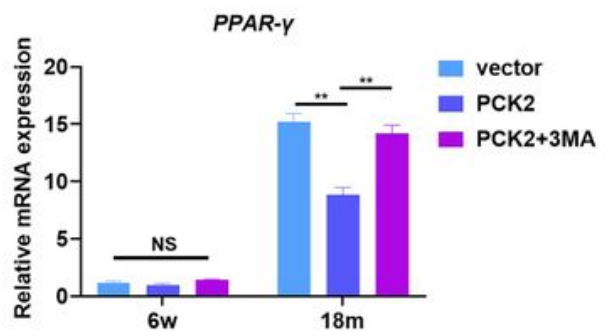

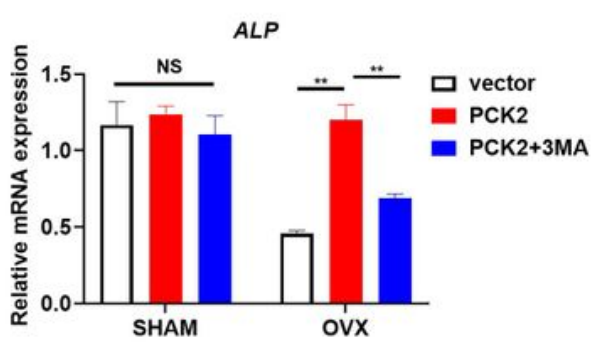

b

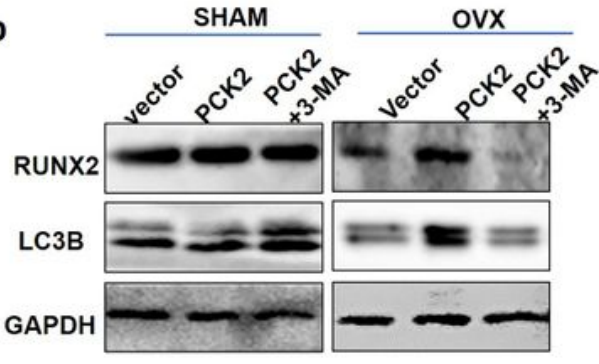

d
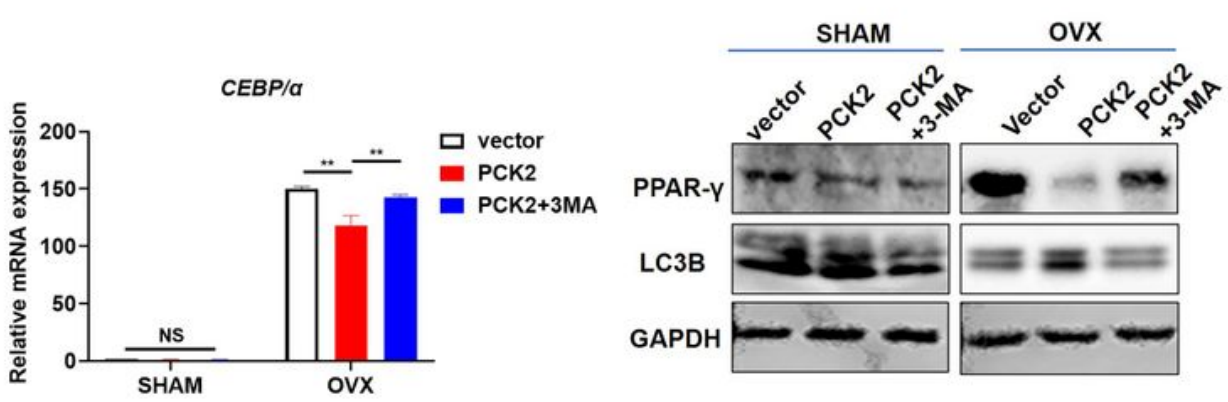

f
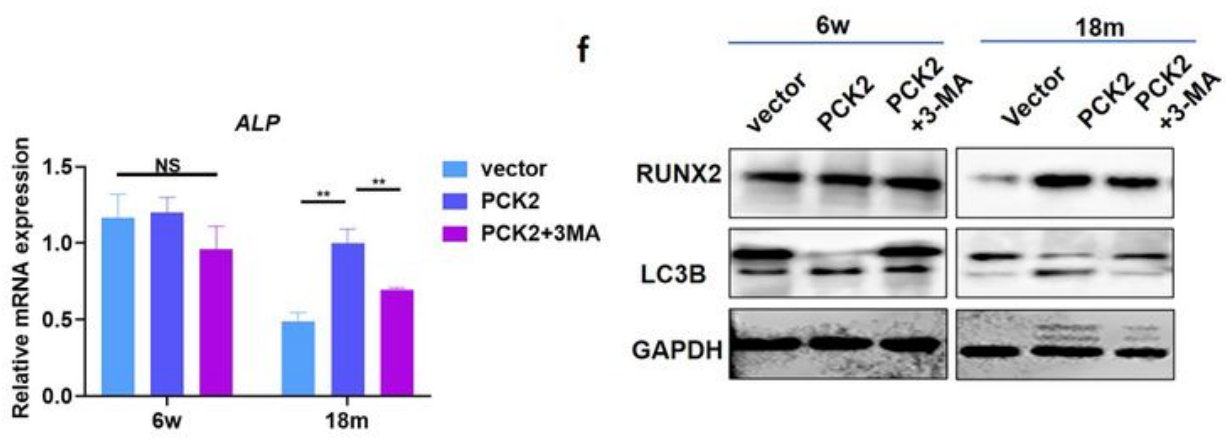

h

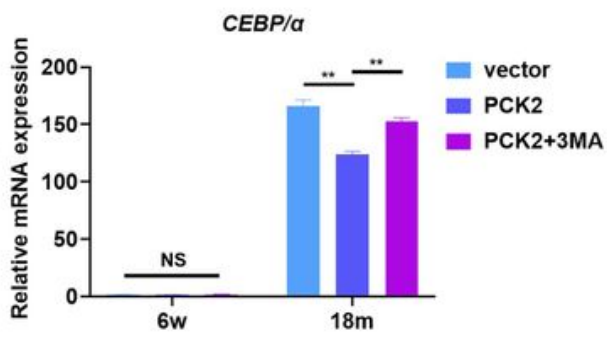

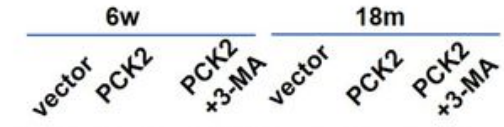

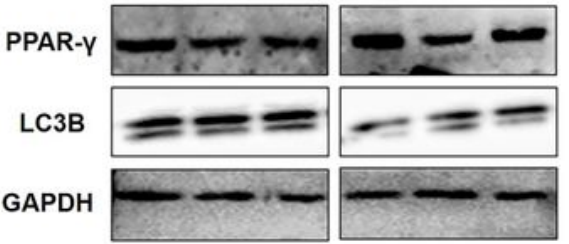

Figure 7

PCK2 rescues the regenerative properties of endogenous BMMSCs in osteoporotic mice through autophagy dependent manner. a The mRNA expressions of RUNX2, ALP and GAPDH in endogenous BMMSCs from SHAM mice with vector, SHAM mice with PCK2, SHAM mice with PCK2 + 3-MA, OVX mice with vector, OVX mice with PCK2, OVX mice with PCK2 + 3-MA, after 7 days of osteogenic induction. $b$ The protein expressions of RUNX2, LC3B and GAPDH in endogenous BMMSCs from SHAM mice with 
vector, SHAM mice with PCK2, SHAM mice with PCK2 + 3-MA, OVX mice with vector, OVX mice with PCK2, OVX mice with PCK2 + 3-MA, after 7 days of osteogenic induction. $c$ The mRNA expressions of PPAR- $Y$ and CEBP/a were tested in endogenous BMMSCs from $6 \mathrm{w}$ mice with vector, $6 \mathrm{w}$ mice with PCK2, $6 \mathrm{w}$ mice with PCK2 + 3-MA, 18m mice with vector, 18m mice with PCK2, 18m mice with PCK2 + 3-MA., after 7 days of adipogenic induction. $d$ Expressions of PPAR- $y$ and LC3B were measured in endogenous BMMSCs from $6 \mathrm{w}$ mice with vector, $6 \mathrm{w}$ mice with PCK2, $6 \mathrm{w}$ mice with PCK2 + 3-MA, $18 \mathrm{~m}$ mice with vector, $18 \mathrm{~m}$ mice with PCK2, 18m mice with PCK2 + 3-MA., after 7 days of adipogenic induction. Data areindicated by the mean $\pm S D$, and all the experiments were carried out in three times. ${ }^{*} P<0.01, N S$ : not significant. 
fig.7

a

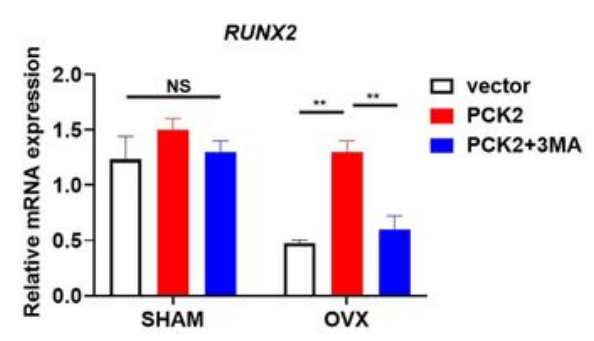

C

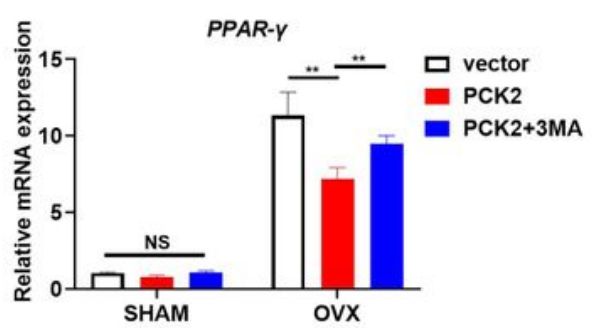

e

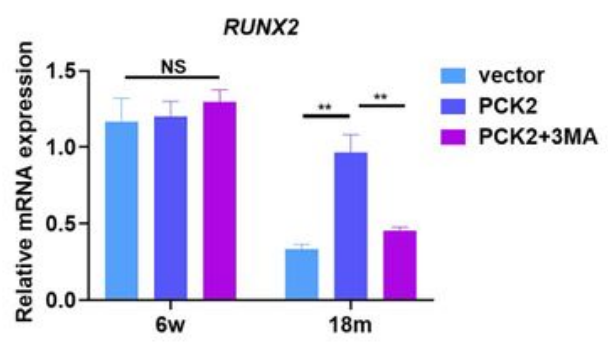

g

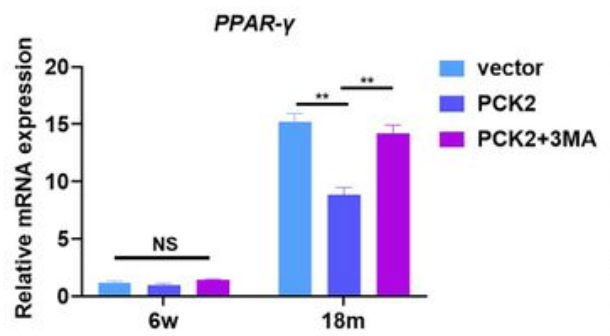

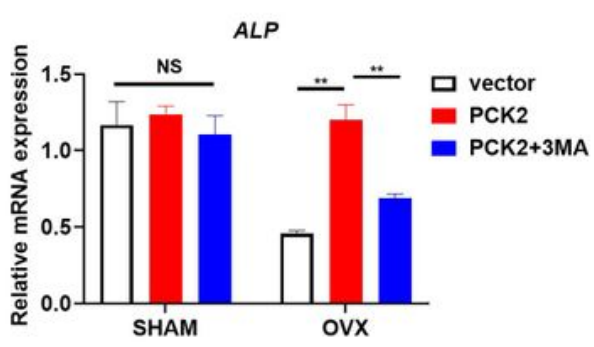

b

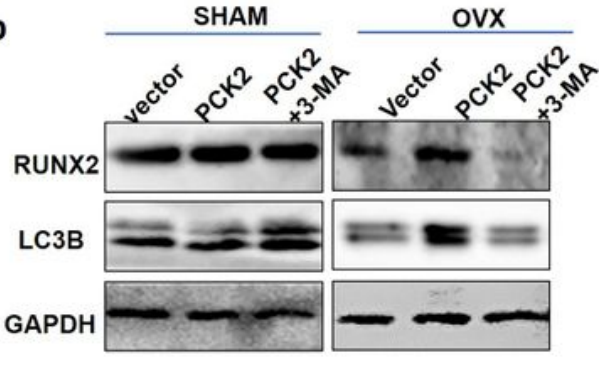

d
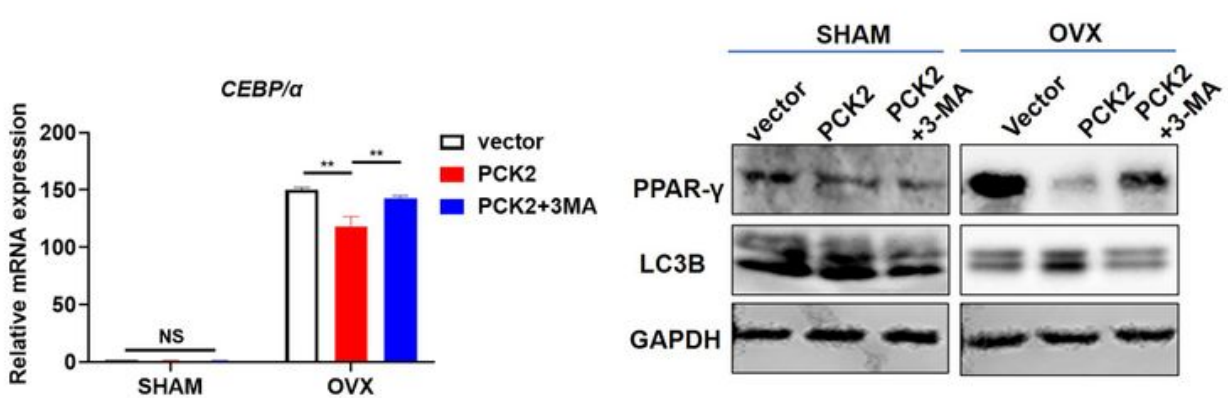

f

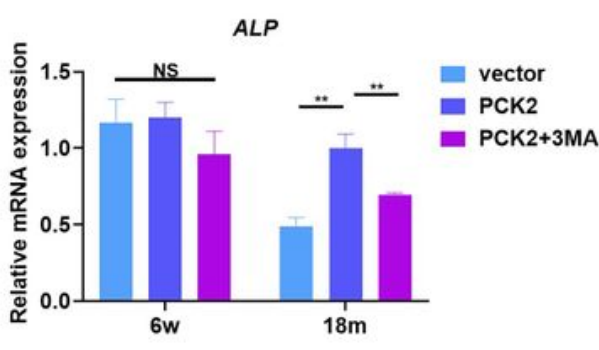

h

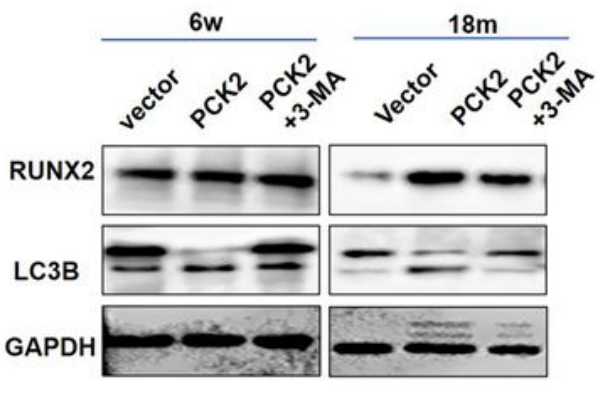

Figure 7
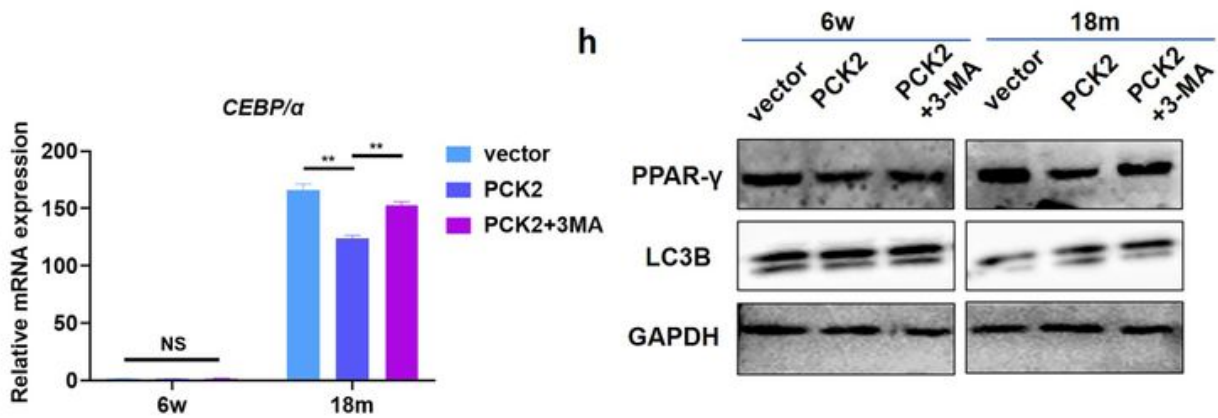

PCK2 rescues the regenerative properties of endogenous BMMSCs in osteoporotic mice through autophagy dependent manner. a The mRNA expressions of RUNX2, ALP and GAPDH in endogenous BMMSCs from SHAM mice with vector, SHAM mice with PCK2, SHAM mice with PCK2 + 3-MA, OVX mice with vector, OVX mice with PCK2, OVX mice with PCK2 + 3-MA, after 7 days of osteogenic induction. $b$ The protein expressions of RUNX2, LC3B and GAPDH in endogenous BMMSCs from SHAM mice with 
vector, SHAM mice with PCK2, SHAM mice with PCK2 + 3-MA, OVX mice with vector, OVX mice with PCK2, OVX mice with PCK2 + 3-MA, after 7 days of osteogenic induction. $c$ The mRNA expressions of PPAR- $Y$ and CEBP/a were tested in endogenous BMMSCs from $6 \mathrm{w}$ mice with vector, $6 \mathrm{w}$ mice with PCK2, $6 \mathrm{w}$ mice with PCK2 + 3-MA, 18m mice with vector, 18m mice with PCK2, 18m mice with PCK2 + 3-MA., after 7 days of adipogenic induction. $d$ Expressions of PPAR- $y$ and LC3B were measured in endogenous BMMSCs from $6 \mathrm{w}$ mice with vector, $6 \mathrm{w}$ mice with PCK2, $6 \mathrm{w}$ mice with PCK2 + 3-MA, $18 \mathrm{~m}$ mice with vector, $18 \mathrm{~m}$ mice with PCK2, 18m mice with PCK2 + 3-MA., after 7 days of adipogenic induction. Data areindicated by the mean $\pm S D$, and all the experiments were carried out in three times. ${ }^{*} P<0.01, N S$ : not significant. 
fig.7

a

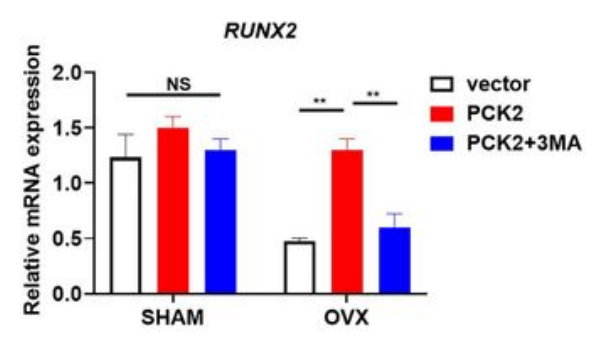

C

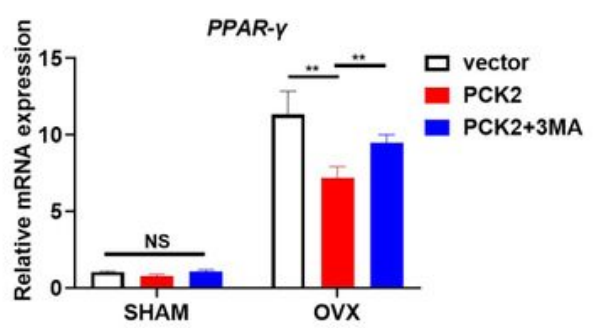

e

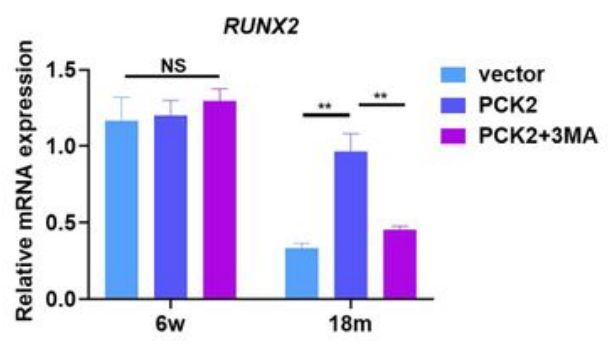

g

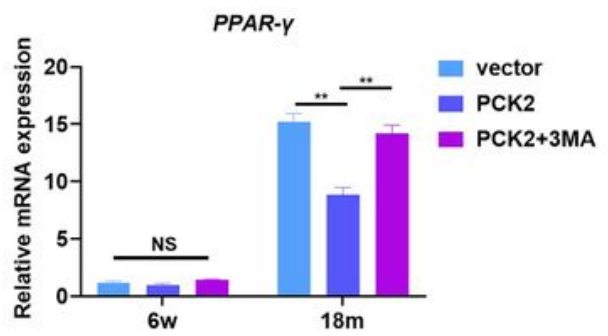

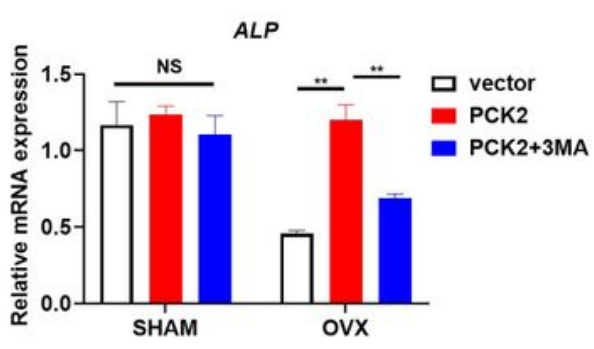

b

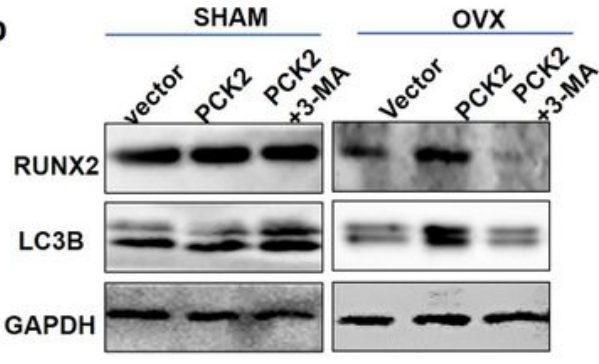

d
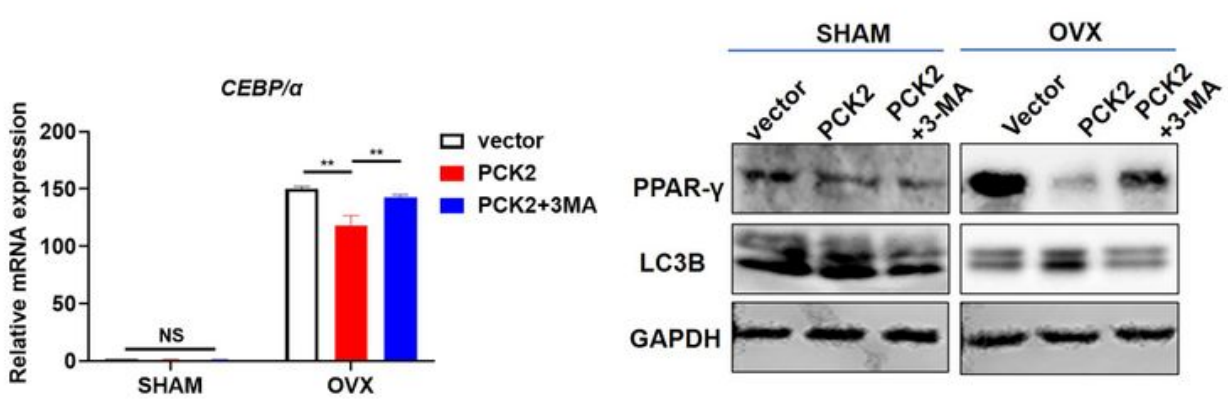

f
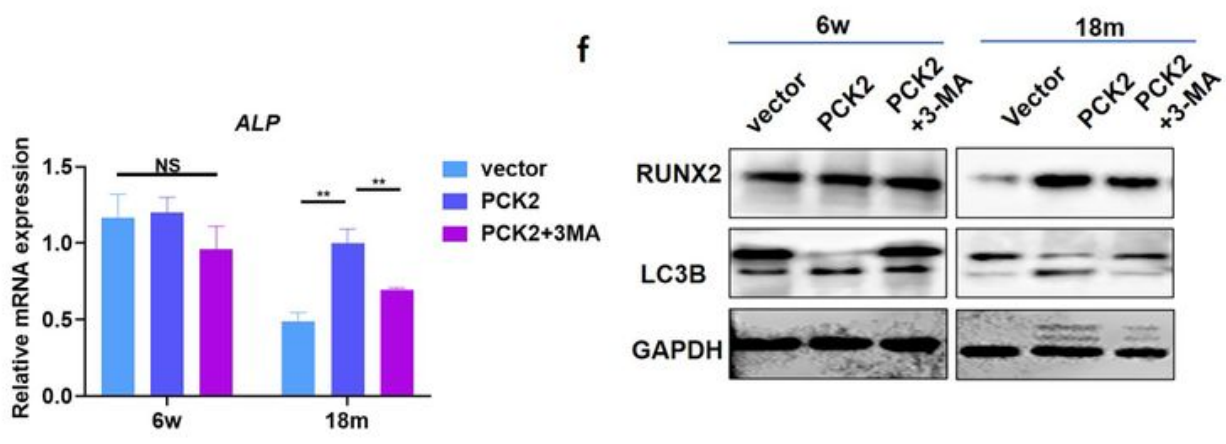

h

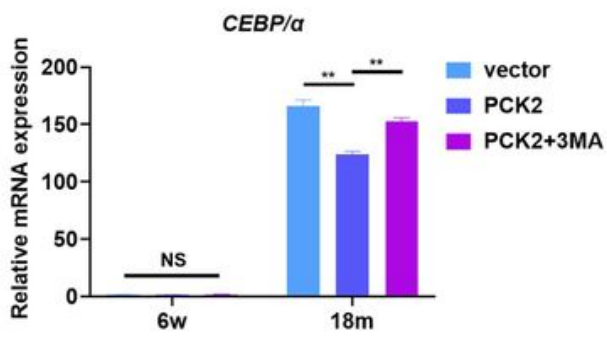

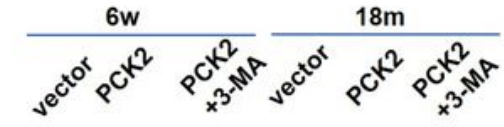

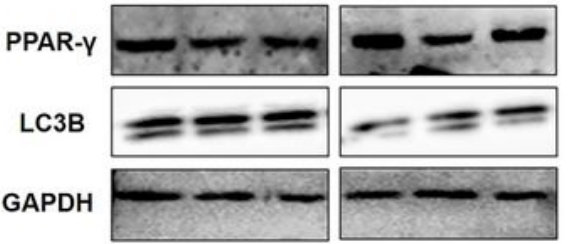

Figure 7

PCK2 rescues the regenerative properties of endogenous BMMSCs in osteoporotic mice through autophagy dependent manner. a The mRNA expressions of RUNX2, ALP and GAPDH in endogenous BMMSCs from SHAM mice with vector, SHAM mice with PCK2, SHAM mice with PCK2 + 3-MA, OVX mice with vector, OVX mice with PCK2, OVX mice with PCK2 + 3-MA, after 7 days of osteogenic induction. $b$ The protein expressions of RUNX2, LC3B and GAPDH in endogenous BMMSCs from SHAM mice with 
vector, SHAM mice with PCK2, SHAM mice with PCK2 + 3-MA, OVX mice with vector, OVX mice with PCK2, OVX mice with PCK2 + 3-MA, after 7 days of osteogenic induction. c The mRNA expressions of PPAR- $Y$ and CEBP/a were tested in endogenous BMMSCs from $6 \mathrm{w}$ mice with vector, $6 \mathrm{w}$ mice with PCK2, $6 \mathrm{w}$ mice with PCK2 + 3-MA, 18m mice with vector, $18 \mathrm{~m}$ mice with PCK2, 18m mice with PCK2 + 3-MA., after 7 days of adipogenic induction. $d$ Expressions of PPAR- $y$ and LC3B were measured in endogenous BMMSCs from $6 \mathrm{w}$ mice with vector, $6 \mathrm{w}$ mice with PCK2, $6 \mathrm{w}$ mice with PCK2 + 3-MA, $18 \mathrm{~m}$ mice with vector, $18 \mathrm{~m}$ mice with PCK2, 18m mice with PCK2 + 3-MA., after 7 days of adipogenic induction. Data areindicated by the mean $\pm S D$, and all the experiments were carried out in three times. ${ }^{\star} \mathrm{P}<0.01$, NS: not significant.

\section{Supplementary Files}

This is a list of supplementary files associated with this preprint. Click to download.

- additionalfileslegends.docx

- additionalfileslegends.docx

- additionalfileslegends.docx

- figureS1.jpg

- figureS1.jpg

- figureS1.jpg

- figureS2.jpg

- figureS2.jpg

- figureS2.jpg

- figureS3.jpg

- figureS3.jpg

- figureS3.jpg

- figureS4.jpg

- figureS4.jpg

- figureS4.jpg

- figureS5.jpg

- figureS5.jpg

- figureS5.jpg

- renamed193f7.docx

- renamed193f7.docx

- renamed193f7.docx

- renamed3f7f6.docx

- renamed3f7f6.docx 
- renamed3f7f6.docx

- renamedb853e.docx

- renamedb853e.docx

- renamedb853e.docx 